This item was submitted to Loughborough's Research Repository by the author.

Items in Figshare are protected by copyright, with all rights reserved, unless otherwise indicated.

\title{
Transportable high-energy high-current inductive storage GW generator
}

\section{PLEASE CITE THE PUBLISHED VERSION}

https://doi.org/10.1109/TPS.2014.2340014

\section{PUBLISHER}

(c) IEEE

\section{VERSION}

AM (Accepted Manuscript)

\section{PUBLISHER STATEMENT}

This work is made available according to the conditions of the Creative Commons Attribution-NonCommercialNoDerivatives 4.0 International (CC BY-NC-ND 4.0) licence. Full details of this licence are available at: https://creativecommons.org/licenses/by-nc-nd/4.0/

\section{LICENCE}

CC BY-NC-ND 4.0

\section{REPOSITORY RECORD}

Novac, Bucur, Ivor Smith, Peter Senior, Michael Parker, Gerry Louverdis, Laurent Pecastaing, Antoine Silvestre De Ferron, Pascal Pignolet, and Sonia Souakri. 2014. "Transportable High-energy High-current Inductive Storage GW Generator". Loughborough University. https://hdl.handle.net/2134/20453. 


\title{
Transportable High-Energy High-Current Inductive Storage GW Generator
}

\author{
Bucur M. Novac, Senior Member, IEEE, Ivor R. Smith, Senior Member, IEEE, Peter Senior, Michael \\ Parker, Gerry Louverdis, Laurent Pecastaing, Antoine de Ferron, Pascal Pignolet and Sonia Souakri
}

\begin{abstract}
A number of high-power applications require a transportable high-energy, high-current GW generator to drive a pulsed power system at the output. A first prototype, based on exploding wire technology and using an H-bridge circuit configuration, was developed at Loughborough University a few years ago and reported previously. The present stage of the work has necessitated the development of a more powerful and energetic source, and this is now based on inductive storage technology. A $400 \mathrm{~kJ}$ capacitor bank is connected by a highCoulomb explosively-driven closing switch with an air-cored 0.6 MV transformer, an exploding wire array and a high-power diode based on a polarity-dependent spark-gap completing the arrangement. The GW generator, including the command and control module, is accommodated in two ISO containers.

The various components of the generator are described in the paper, together with results obtained from full-scale tests.
\end{abstract}

Index Terms-Closing switches, exploding wires, high-voltage technology, inductive storage, opening switches, pulse transformers

\section{INTRODUCTION}

$\mathrm{D}$ URING a large scale experimental program, it was necessary to supply a powerful impulse of many GWs to a system having a resistance of at least ten ohms and a selfinductance of many tens of micro-henrys. Such a load is uncommon in conventional high-energy, high-power applications and the design of the source that was required necessitated very careful consideration. Initially, a generator based on a capacitor bank storing only a few tens of kJs of energy was developed [1]. The arrangement, using an $\mathrm{H}-$ configuration circuit with a high-voltage ballast inductor and an exploding wire array contained in each pair of the

Manuscript received 2013

B. M. Novac, I. R. Smith and P. Senior are with the School of Electronic, Electrical and Systems Engineering, Loughborough University, Loughborough, Leicestershire LE11 3TU, UK (phone: +44(0)1509-227-048; fax: 44(0)1509-227-014 ; e-mail: B.M.Novac@ lboro.ac.uk)

M. Parker was with Loughborough University, Loughborough, Leicestershire LE11 3TU, UK. He is now with BAE Systems, Advanced Technology Centre, West Hanningfield Road, Great Baddow, Chelmsford, Essex CM2 8HN, UK

Gerry Louiverdis is with Dstl, Fort Halstead, Sevenoaks, Kent TH14 7BP, UK

L. Pecastaing, A. Silvestre De Ferron, P. Pignolet and Sonia Souakri are with the Laboratoire SIAME, Equipe Génie Electrique, Université de Pau et des Pays de l'Adour, Hélioparc Pau-Pyrénées, 2 av Angot 64053 Pau cedex 9, France (e-mail: laurent.pecastaing@univ-pau.fr). diagonally opposite arms, successfully generated a peak output voltage of $300 \mathrm{kV}$ and a load current of about $6 \mathrm{kA}$. Scaling-up the low-energy generator proved however difficult and led to the successful development of a novel high-energy generator, based on inductive energy storage technology.

The inductive energy storage technique was considered in the early 1960s in relation to high-energy plasma fusion projects. There are two great advantages of using inductive storage systems rather than capacitive storage based power sources: the magnetic energy density can be several thousand times greater than the electrostatic energy density and at a much lower cost [2]. The difficulty is that while a capacitive storage system naturally requires a closing switch an inductive storage system also needs an efficient opening switch and, as pulsed power practice has demonstrated many times, an opening switch is always more difficult to develop than a closing switch. An inductive storage system can also contain a transformer, used to match the system with a high-impedance load that requires a high-voltage pulse at a relatively low current. Such type of circuit, which is used in the present work, has been described previously [3-5]. As detailed below, the three novelties contained in the present paper are: an aircore transformer capable of withstanding very large magnetic forces, an inter-winding connection enabling (after the action of the opening switch) the generation of a very long current pulse in the load and the use of a high-voltage diode to attach the load.

The paper details the components of the novel inductive energy storage generator and shows that, a two-step development was required for two critical items, before they could reliably be incorporated in the overall arrangement. Data obtained during generator testing is presented and compared with predictions based on theoretical modelling.

\section{GENERATOR OVERVIEW}

Fig. 1 shows that the electrical equivalent circuit of the generator contains a capacitor bank $(C)$, a high-voltage transformer $(H V T)$, two closing switches $\left(S_{1}\right.$ and $\left.S_{2}\right)$ and an 'opening switch' in the form of an exploding wire array $(E W A)$. The primary winding circuit of the HVT includes the high-Coulomb closing switch $S_{I}$ that triggers the discharge of the capacitor bank, generating a current that charges the primary winding self-inductance $L_{P}$ with magnetic energy and at the same time deposits Joule energy in the EWA. At the time the discharge begins, the time rate-of-change of this 


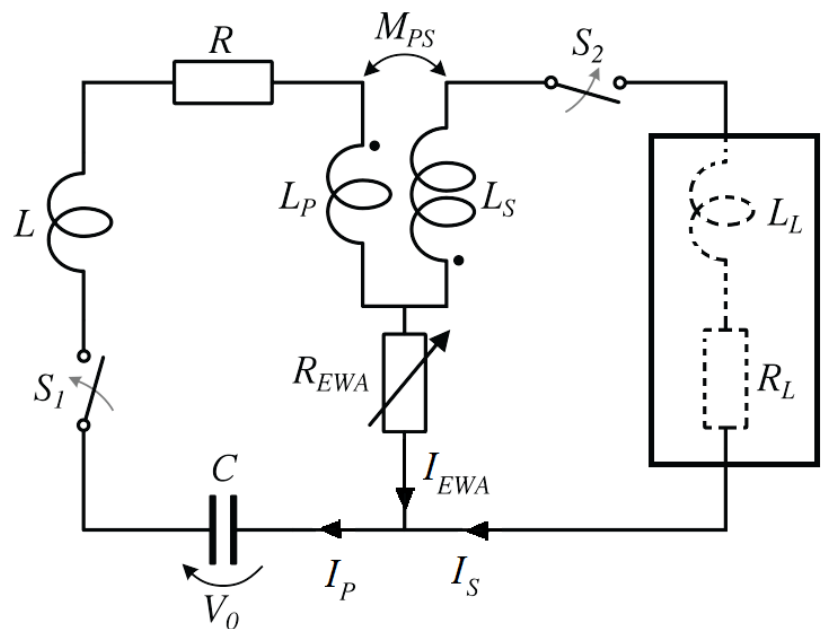

Fig. 1. Equivalent electrical scheme of the inductive-storage high-energy pulsed power generator.

current has a relatively high (positive) value, inducing a negative polarity precursor voltage pulse in the secondary winding. As the deposited Joule energy increases the wires explode, with the solid copper transformed firstly into liquid and finally into an ionised gas while the EWA resistance increases hundreds of times and a high-voltage is generated across the array (i.e., the circuit 'opens'). Another consequence of the high resistance excursion of the EWA is the generation of a large (negative) time rate-of-charge of the current, which in turn produces by induction a very highvoltage positive polarity impulse across the secondary winding of the HVT. The circuit is closed by the electrical selfbreakdown of the high-voltage spark gap $S_{2}$ with part of the magnetic energy stored in $L_{P}$ being transferred into the selfinductance of the secondary winding circuit. The switch $S_{2}$ acts as a diode, removing the unwanted negative voltage precursor and connecting the load only as the voltage becomes positive. This action conditions the load current by reducing its rise time in comparison with the rise time should the load be connected at the beginning of the capacitor bank discharge (i.e., $S_{2}$ is closed at all times).

An interesting and novel feature of the present generator is the interconnection provided between the two transformer windings, which enables the load to be powered with a long duration slowly decaying current. The operation is as follows: once the EWA 'opens' the current $I_{E W A}$ in the EWA becomes negligible and the load current $I_{L}$ is practically equal to the primary current $I_{P}$, allowing the load to remain energized for a long period of time determined by the characteristic time constant of the circuit: $\left(R+R_{L}\right) C$. The differential equations governing the generator circuits together with a detailed analysis are presented later.

The components of the primary winding circuit are:

- a capacitor bank containing eight capacitors type General Atomic Energy Products (GAEP) 32349 [6], with a combined capacitance $C=1715 \mu \mathrm{F}$. When charged to its rated voltage $V_{o}$ $=22 \mathrm{kV}$, by a $8 \mathrm{~kJ} / \mathrm{s}$ charger type GAEP CCS08020P1D [6], the bank stores $415 \mathrm{~kJ}$;

- a high-Coulomb closing switch $S_{l}$, similar to that described in [1], operated using up to five detonators. In the tests described later it was always driven by only three detonators, when the switch self-inductance was only $0.5 \mathrm{nH}$ and its effective resistance less than $0.5 \mathrm{~m} \Omega$;

- an opening switch EWA made from $99.99 \%$, temper annealed, oxygen free, high conductivity (OFHC C110) copper wires, each $500 \mu \mathrm{m}$ in diameter and up to $500 \mathrm{~mm}$ long. Each wire is housed in an acrylic cylindrical cartridge filled with $40 \mu \mathrm{m}$ glass beads (sand) and sealed with hot melt glue. The EWA arrangement allows a total of up to 20 cartridges to be mounted.

The total self-inductance and resistance of the primary winding circuit at the beginning of a discharge are $L=60 \mathrm{nH}$ and $R=3.1 \mathrm{~m} \Omega$. These values exclude the contribution from the $H V T$ primary winding but include those from the capacitor bank $(10 \mathrm{nH}, 1 \mathrm{~m} \Omega)$, transmission lines $(12 \mathrm{nH}$, negligible resistance), detonator-activated closing switch $S_{1}(0.5 \mathrm{nH}$, $0.5 \mathrm{~m} \Omega$ ) and an EWA using 16 wires, each $300 \mathrm{~mm}$ long $(38 \mathrm{nH}, 1.6 \mathrm{~m} \Omega)$.

Fig. 2 shows a block-diagram of the overall generator assembly which was installed in a $20 \mathrm{ft}$ ISO container with Figs. 3 and 4 showing some of the important constituent parts. As presented in Fig. 2, the pulsed power generator requires two capacitor banks: a high-energy high-voltage unit $(415 \mathrm{~kJ} / 22 \mathrm{kV})$ to drive the generator and a low-energy lowvoltage unit $(10 \mathrm{~J} / 4.5 \mathrm{kV})$ to trigger the detonators used to operate the switch $S_{1}$. Both banks have dedicated high-voltage chargers which are each monitored using a DC high-voltage probe coupled to a laptop via a picoscope and a fiber-optic interface. For both banks, ancillary 'isolate and dump' systems are used to disconnect the chargers during a shot or to release the bank energy into high-value resistors if the test needs to be aborted. All capacitor bank instrumentation is controlled via pneumatics and fiber-optics from a command and control module installed in a separate 10ft ISO container (Fig. 4(d)), with both containers powered by dedicated diesel generators. Details of the diagnostic instrumentation shown in Fig. 2 are presented later.

\section{DEVELOPMENT OF CRITICAL COMPONENTS}

\section{A. Development of the air-core HVTs}

\section{1) The development of the helical HVT}

HVTs for use in high-power systems are normally constructed in either a spiral-strip configuration [5], with the primary and secondary windings both of copper sheet, or a helical arrangement [7] in which the secondary winding is made using a relatively thin round copper conductor. More recently, a further design has appeared [8], with a coaxial primary and a toroidal secondary winding made from insulated cable. The merits and drawbacks of all three designs are summarized in Table I.

After discarding the spiral-strip design for reasons mainly related to simplicity, a first version of the $H V T$ was constructed using the technique employed in many Tesla-type air-core transformers previously developed at Loughborough (Fig. 5). The primary winding is a single-turn copper strip 


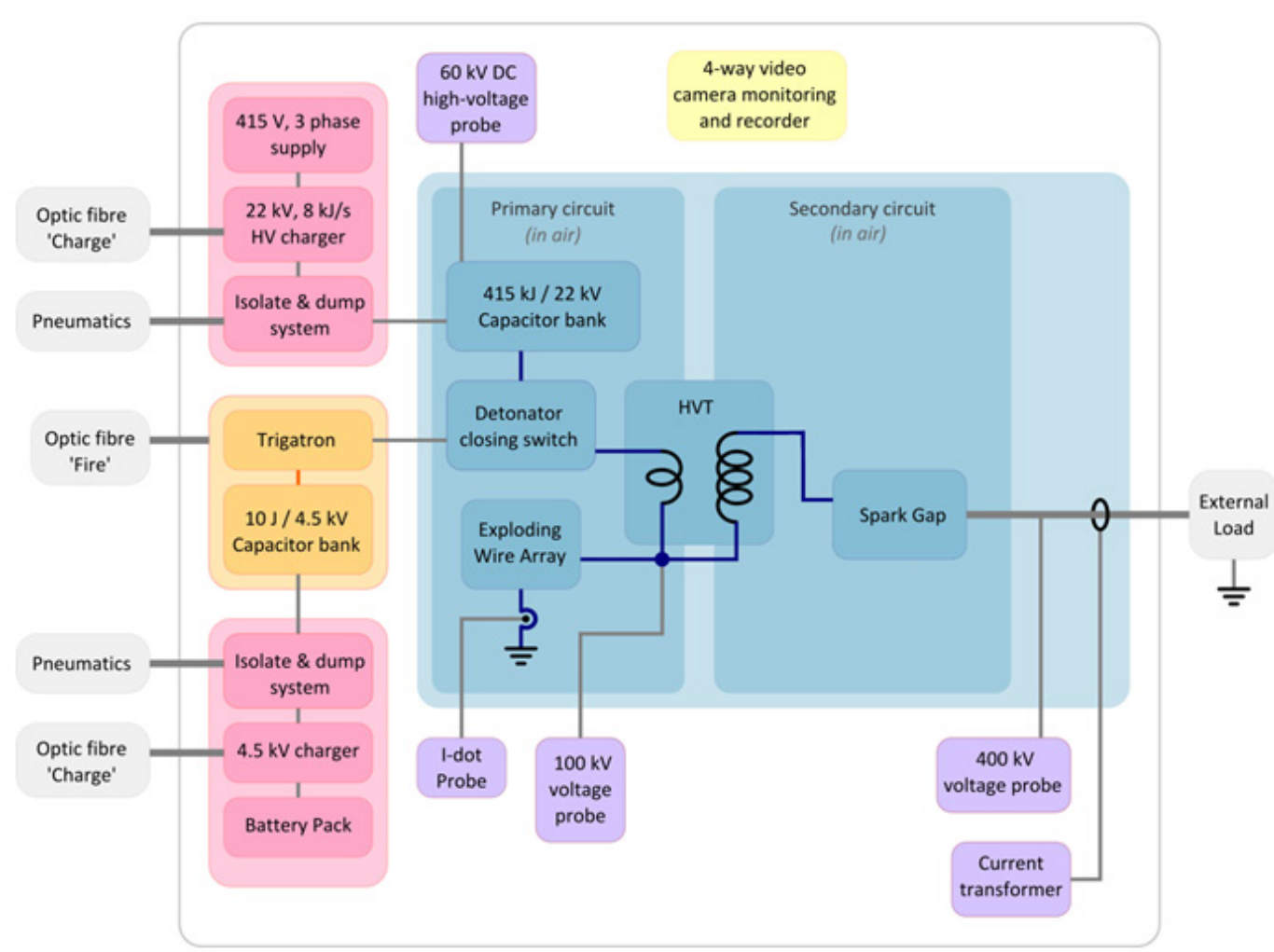

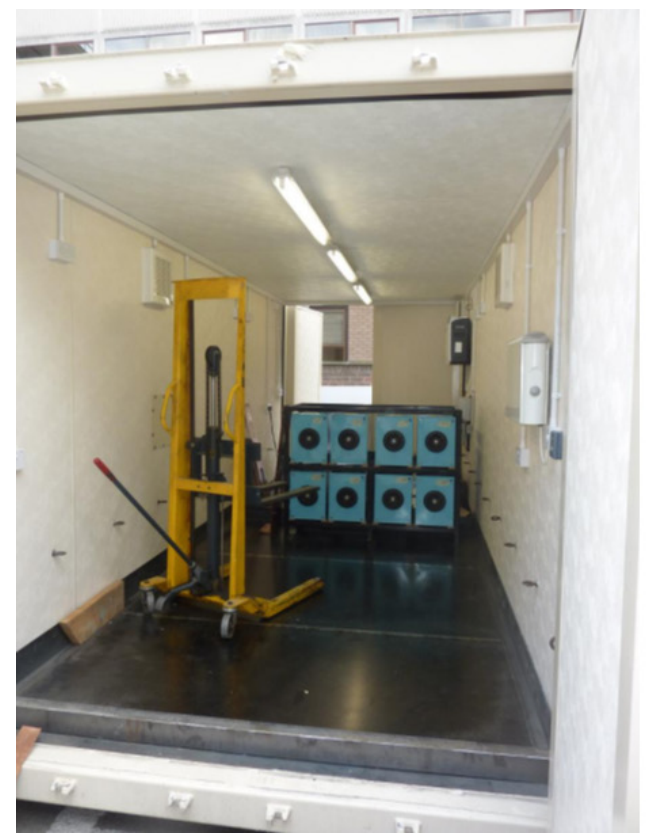

a)

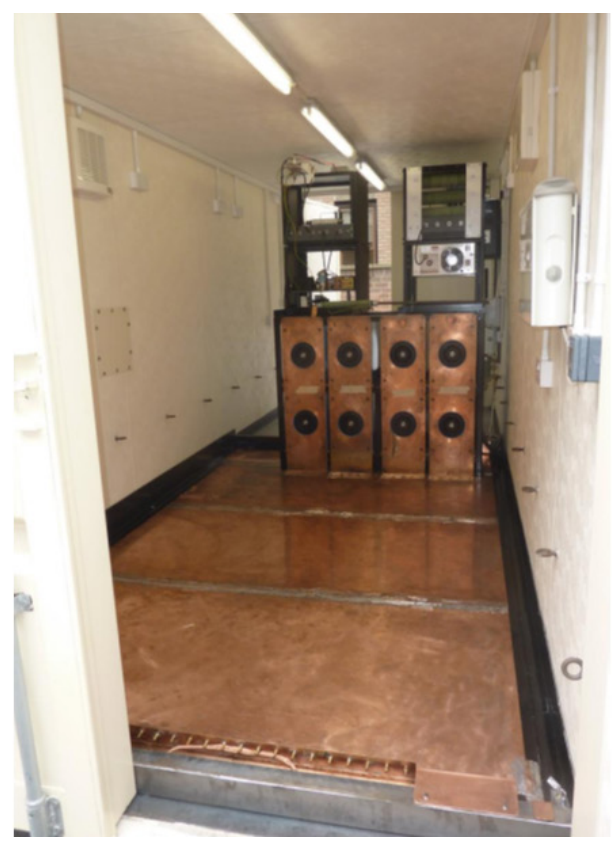

b)

Fig. 3. Aspects from the installation of the $400 \mathrm{~kJ}$ bank inside a $20 \mathrm{ft}$ ISO container of dimensions: length $6.1 \mathrm{~m}(20 \mathrm{ft})$, width $2.44 \mathrm{~m}$ and height $2.59 \mathrm{~m}$ a) capacitors positioned (b) bank connected to copper ground (part of the stripline).

$100 \mathrm{~mm}$ wide by $5 \mathrm{~mm}$ thick, rolled into a $490 \mathrm{~mm}$ inner diameter loop and secured on the outside of a polyethylene oil-filled drum. The secondary winding has 14 turns, with a constant pitch of $8.47 \mathrm{~mm}$, wound on a polyethylene mandrel grooved to locate the wire, as shown in Fig 5(a) and mounted inside the polyethylene drum. The first 9 turns are coaxialhelical with a (constant) inner diameter of $457 \mathrm{~mm}$ and the last
5 are conical-helical, with the taper linearly reducing the diameter for additional high-voltage insulation to $444 \mathrm{~mm}$. In reference to Fig. 1, the inductances of the helical HVT were calculated by filamentary modelling [9] as $L_{P}=767 \mathrm{nH}, L_{S}=$ $128 \mu \mathrm{H}$ and $M_{P S}=8 \mu \mathrm{H}$, which give a magnetic coupling coefficient $\mathrm{k}=0.807$. Preliminary low voltage experiments confirmed these values. 


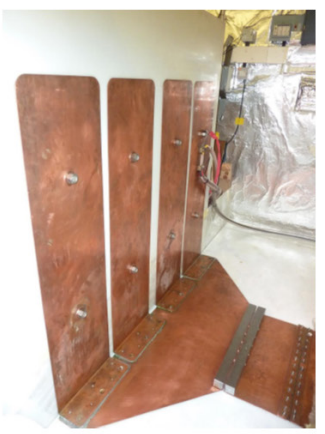

a)

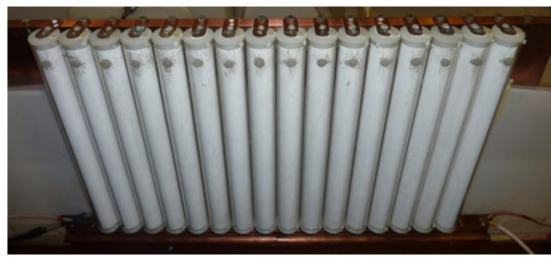

c)

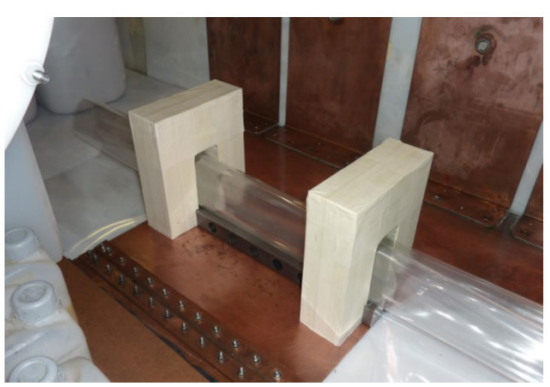

b)

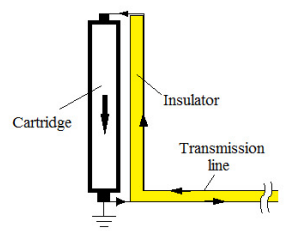

d)

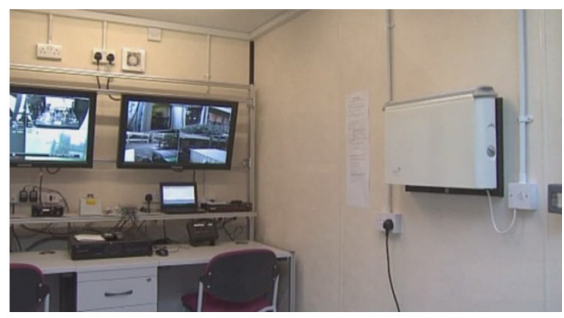

e)

Fig. 4. Components of the pulsed power generator a) the high-voltage side of the stripline connected between capacitor bank and switch $S_{I}$; b)Detonator-activated high-Coulomb closing switch $S_{I}$ c) Opening switch: exploding wire array $(E W A)$ with 16 cartridges connected in parallel; for $E W A$ details see text d) Details showing a $E W A$ cartridge mounted at the end of the transmission line; the direction of current flow is also indicated e) Command and control module installed inside a 10ft ISO container

TABLE I

RELATIVE MERITS AND DRAWBACKS OF THREE HVT DESIGNS WHEN USED IN HIGH-POWER SYSTEMS

\begin{tabular}{|c|c|c|}
\hline Type & Advantages & Disadvantages $^{\text {a }}$ \\
\hline Spiral-strip & $\begin{array}{l}\text { - high coupling coefficient possible }(>0.9) \\
\text { - can carry high currents ( }>1 \mathrm{MA}) \text { in both winding } \\
\text { circuits } \\
\text { - } \quad \text { coaxial output as required by most loads } \\
\text { - can be scaled to multi-MV operation (but only when } \\
\text { immersed in a liquid such as oil or solution of CuSO4) }\end{array}$ & $\begin{array}{l}\text { - primary input easily coupled to a parallel } \\
\text { transmission line but requires an adaptor ('fish-tail') to } \\
\text { couple to coaxial configurations } \\
\text { - elaborate manufacturing due to voltage grading and } \\
\text { other techniques required to handle the high electric } \\
\text { fields generated by strip edges } \\
\text { - high secondary capacitance }\end{array}$ \\
\hline Helical & 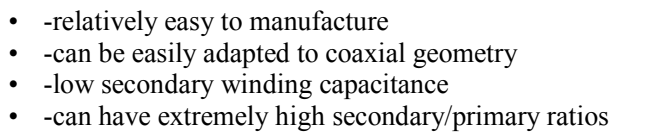 & $\begin{array}{l}\text { - low coupling coefficient }(<0.8) \\
\text { - difficult to scale up above } 1 \mathrm{MV} \\
\text { - } \text { cannot drive high currents in the secondary winding }\end{array}$ \\
\hline Coaxial & $\begin{array}{l}\text { - high coupling coefficient possible }(>0.9) \\
\text { - does not require oil or pressurised gas } \\
\text { - } \text { can be scaled to multi-MV operation } \\
\text { - } \text { can carry a high current }(>1 \mathrm{MA}) \text { in the primary circuit } \\
\text { - } \text { relatively easy to manufacture } \\
\text { - extremely robust, able to handle very large forces } \\
\text { - coaxial input } \\
\text { - } \text { very low secondary winding capacitance }\end{array}$ & $\begin{array}{l}\text { - the output is not coaxial } \\
\text { - cannot drive large currents in the secondary winding }\end{array}$ \\
\hline
\end{tabular}




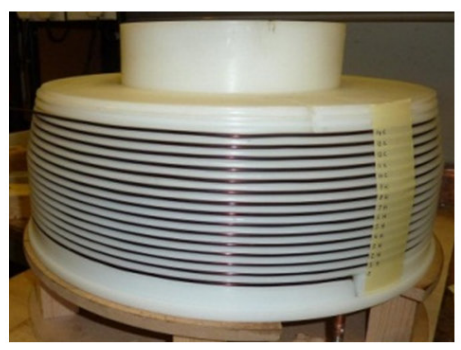

a)
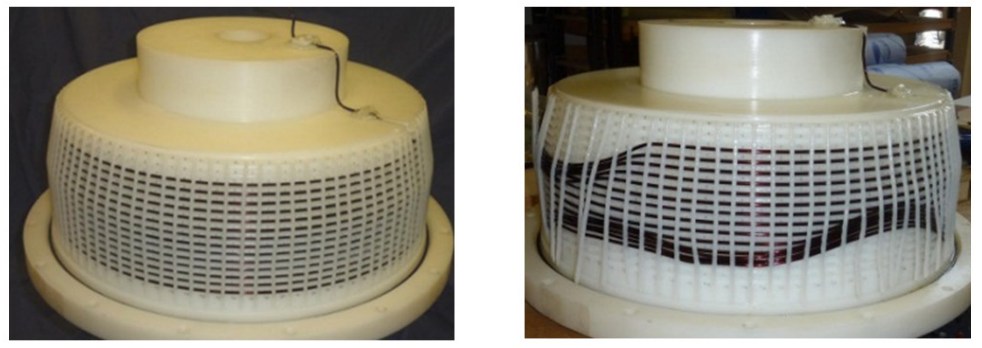

b)

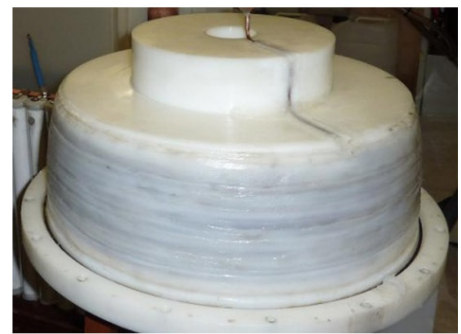

c)

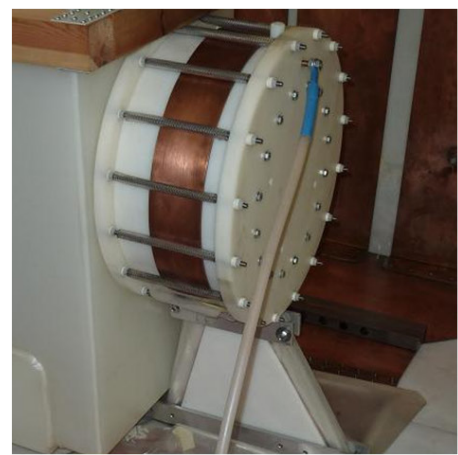

d)

Fig. 5. Development of the helical HVT (overall length $150 \mathrm{~mm}$, outer diameter $500 \mathrm{~mm}$ ). a) secondary winding b) left: winding design using polyethylene strips welded to the plastic former to hold the wire in position; right: same winding shown after a high-energy shot c) final design using a completely encapsulated secondary winding d) helical $H V T$ transformer mounted onto the wall of an oil tank containing the secondary switch $S_{2}$ and, during preliminary testing, a resistive load.

In an effort to increase the mechanical inertia, the secondary was wound with $4 \mathrm{~mm}$ diameter, but the forces generated of about 2 tons per turn still pulled the wire out of the mandrel groove. This occurred even when the additional restraining technique shown in Fig. 5(b) and various other approaches were adopted. The final elegant and simple solution was to fill the mandrel grooves above the wire by polyethylene welding, thus completely encapsulating the winding as seen in Fig. 5(c). The resulting helical HVT (Fig. 5(d)), still requires oil to insulate its output, but has so far successfully survived a number of high-energy shots in which the load current was of the order of $10 \mathrm{kA}$. The helical $H V T$ allows a voltage probe to be mounted at the secondary output which was extremely useful in facilitating the detailed analysis presented later, related to the extreme peak voltage induced when $S_{2}$ opens, and helped in highlighting an important design issue. However, because it was decided to abandon the use of oil in the generator when mounted inside a container together with the need to produce much greater load currents in subsequent work attention turned to the alternative of a coaxial design.

\section{2) The development of the helical HVT}

The artistic view of a coaxial $H V T$ of Fig. 6 shows the outer conductor of the coaxial single-turn primary winding, in which 


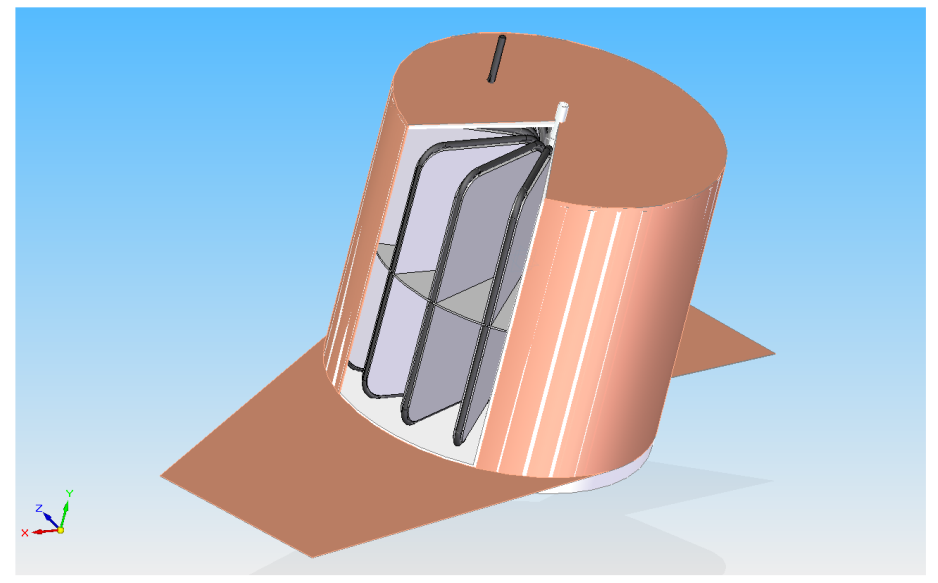

a)

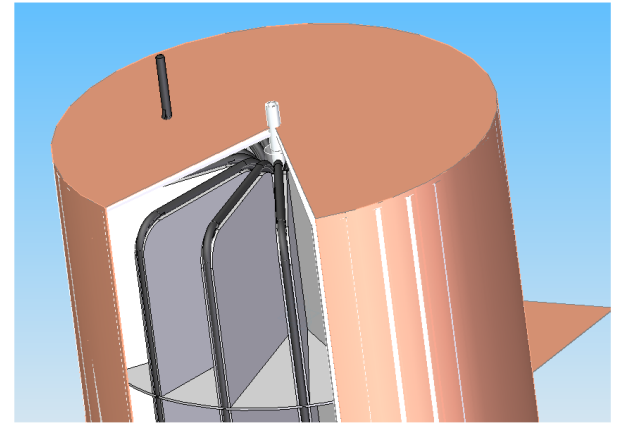

b)

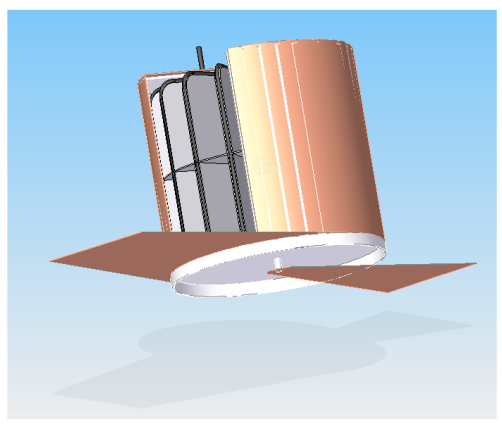

c)

Fig. 6. a) Artistic view of a coaxial $H V T$ with part of the outer copper conductor removed b) details of the secondary winding: the HV output can be observed as an insulated cable passing through a hole in the top of the outer copper layer at the short-circuited end c) details of the primary winding with connections to the driving source shown

the current flow is axial (Fig. 6(a) and 6(c)) and the multi-turn toroidal secondary winding located within the primary winding (Fig. 6(a) and 6(b)).

The primary winding coaxial is open at one end (Fig. 6c) and short-circuited at the other. The inner conductor located at the center is a thick aluminum tube covered with a thick insulating tube and connected to a plate. The outer coaxial conductor is a relatively thin copper layer mounted on a thick plastic support, the 'top-hat' insulator, and connected to a second plate. Fig. 6(c) shows the two plates, which are inserted in the upper high-voltage part of the capacitor bank transmission line (Fig. 4a), between the switch $S_{I}$ (Fig. 4b) and the EWA (Fig. 4c).

The toroidal secondary winding is made from insulated cable and mounted on a very thick cylindrical plastic former inside the primary winding. The input to the secondary winding is attached to the central aluminum tube to provide the necessary inter-winding interconnection and, as Fig. $6 \mathrm{~b}$ shows, the high-voltage output exits via a well-insulated hole made in the outer copper layer. Design of the HVT requires accurate calculation of all the three transformer inductances, together with their dynamic resistances (taking both into skin and proximity effects into account) and finally the electromagnetic forces acting on the $H V T$ structure during a shot. The specific methods used to calculate these details are explained below.

3) Calculation of self and mutual inductance

The self-inductances of both the primary and secondary windings can be obtained from standard textbook formulae [10]:

$$
\begin{aligned}
& L_{P}=\frac{\mu_{0} Z_{\max }}{2 \pi} \ln \left(\frac{R_{P}}{r_{P}}\right) \\
& L_{S}^{E}=\frac{\mu_{0} N^{2}\left(Z_{\max }-Z_{c}\right)}{2 \pi} \ln \left(\frac{R_{S}}{r_{S}}\right)
\end{aligned}
$$

where $Z_{\max }$ is the axial length of the $H V T$ and $Z_{c}$ is twice the bending radius of the secondary winding cables. $R$ and $r$ are outer and inner radii and subscripts $P$ and $S$ indicate respectively the primary and secondary windings. Both equations are valid only for $Z_{\max }>>R$ (with $R>r$ ).

When cylindrical coordinates $(r, \theta, z)$ are used it is wellknown that in a coaxial structure, with a current flowing along $z$-axis, the magnetic flux-density generated is circular $\left(B_{\theta}\right)$. It then follows that the mutual inductance can be obtained from an equation similar to Eq. 1 to determine the magnetic flux linking one turn of the secondary winding. For $N$ turns the 
result is:

$$
M_{P S}=\frac{\mu_{0} N\left(Z_{\max }-Z_{C}\right)}{2 \pi} \ln \left(\frac{R_{S}}{r_{S}}\right)
$$

which provides a conservative figure due to neglect of the (small) magnetic flux linked to the two regions where the cables are bent.

The errors involved in Eq. 2 cannot be readily estimated, and an analysis was therefore undertaken using a more precise method of calculation. Each turn was regarded as a plane rectangle made from four very thin straight metallic wires, with the Biot-Savart formula used to calculate the magnetic flux density distribution produced by a current flowing round the rectangle. The result is used in determining the mutual inductance between the various pairs of turns $M_{i, j}$ circularly positioned with an angle $2 \pi / N$ between any adjacent pair. With the self-inductance of each turn $\left(L_{i}\right)$ obtained using a standard textbook formula [10], the calculated overall secondary winding self-inductance is given by:

$$
L_{S}^{C}=\sum_{i=1}^{N} L_{i}+\frac{1}{2} \sum_{i, j=1}^{N} M_{i, j}
$$

In most cases studied so far, the difference between the estimate provided by Eq. 2 and the more precise result obtained using Eq. 4 turns out to be very small, with the estimate typically being about $1.5 \%$ larger than the more precise figure.

\section{4) Calculation of dynamic resistance}

Although the calculation of the dynamic resistances of all the HVT components, using both skin and proximity effects, can readily be performed this was unnecessary in the present study, as the resistance introduced by the EWA in the primary winding circuit and the load system in the secondary winding circuit are some two-orders of magnitude greater.

\section{5) Calculation of forces}

Between the primary coaxial conductors, the magnetic flux density generated by a primary current $I_{P}$ flowing through the aluminum tube can be obtained using the Ampère's Circuital Law [10] as $B(r)=\frac{\mu_{0} I_{P}}{2 \pi r}$, assuming $r_{P}<r<R_{P}$. This magnetic field interacts with a secondary current Is flowing through the inner $(i)$ and outer $(o)$ straight axial section of length $Z_{\max }-Z_{C}$ of each secondary winding rectangle, with the resulting radial Ampère's forces [10] being:

$$
\begin{aligned}
& F_{r}^{i}=\frac{\mu_{0} I_{p} I_{S}}{2 \pi r_{s}}\left(Z_{\max }-Z_{C}\right) \\
& F_{r}^{o}=\frac{\mu_{0} I_{p} I_{S}}{2 \pi R_{s}}\left(Z_{\max }-Z_{C}\right)
\end{aligned}
$$

\section{6) Final design characteristics}

After considering all aspects related to implementing the $H V T$ into the pulsed power circuit of Fig. 1, the following design parameters were established:

i) Coaxial primary winding: axial length $Z_{\max }=1.5 \mathrm{~m}$; central part made from a $10 \mathrm{~mm}$ thick aluminum cylinder with $r_{P}=$ $53 \mathrm{~mm}$; outer part made from a $2 \mathrm{~mm}$ thick copper sheet with $R_{P}=778 \mathrm{~mm}$ ii) Toroidal secondary winding: $N=15$ turns made from a $H V$ cable, each with $r_{S}=91 \mathrm{~mm}$ and $R_{S}=778 \mathrm{~mm}$. The minimum bending radius specified by the cable manufacturer is $150 \mathrm{~mm}$, resulting in $Z_{C}=300 \mathrm{~mm}$.

The resulting electrical parameters are: $L_{P}=886.52 \mathrm{nH}, L_{S}$ $=127.69 \mu \mathrm{H}$ and $M_{P S}=8.51 \mu \mathrm{H}$, with the magnetic coupling coefficient estimated as $k_{\text {theory }} \approx 0.8$. This value was later confirmed during preliminary testing as $k_{\text {exp }}=0.806$.

It will be noted that coaxial transformers can easily be produced with coupling coefficients in excess of 0.9 . However, as the most stringent requirement for the present transformer is to withstand a large number of shots whilst extremely heavy loaded due to electromagnetically generated forces, all the insulation employed has a thickness much greater than that necessary to prevent electrical breakdown. For example, the thickness of the cylindrical insulator covering the central metallic tube is $20 \mathrm{~mm}$, well above that dictated by electric breakdown requirements. This inevitably reduced the values of the mutual inductance.

7) Preliminary testing of the secondary winding high-voltage cable

The high-voltage cable used in the manufacture of the present coaxial HVT is type C2236, from series 2400 of the $\mathrm{x}$ ray cables produced by Essex X-ray [11]. The cable is coaxial with an overall outer diameter of $38 \mathrm{~mm}$, it can withstand $250 \mathrm{kV}$ DC and has a core made from a collection of three stranded wires covered with rubber (ethylene propylene diene monomer). After removing the outer protective PVC jacket and the metallic braid, the overall outer diameter of the remaining cable is $32.5 \mathrm{~mm}$ and it was used as such in the construction of the transformer i.e., no effort was made to remove the semiconductor layer, resulting a cable weighing less than $1.7 \mathrm{~kg} / \mathrm{m}$.

The calculated peak values for the HVT currents of $I_{P}=$ $400 \mathrm{kA}$ and $I_{S}=20 \mathrm{kA}$ result in large radial forces: $F^{i}=2.2$ tons $(18.3 \mathrm{~kg} / \mathrm{cm})$ and $F^{o}=0.25$ tons $(2.1 \mathrm{~kg} / \mathrm{cm})$.

However, the generator is required on occasions to produce a bipolar current $\left(S_{2}\right.$ permanently closed), resulting in radial forces that change in direction. In time this effect may lead to internal damage to the cable, in ways that are particularly difficult to estimate. Instead of a long and tedious investigation, it was decided to test the cable against a force considerable higher than the 'normal' peak force calculated above. A section of the high-voltage cable was used as part of a parallel transmission line and, by discharging the Quattro bank [5], the sinusoidal current shown in Fig. 7, with a $280 \mathrm{kA}$ peak, was passed through the cable. The corresponding force acting on the inner stranded wires was calculated as $262 \mathrm{~kg} / \mathrm{cm}$ i.e., 16 times larger than the peak force experienced under normal operation, and the experiment was repeated twice. 'Post-mortem' investigation, performed by cutting the cable into two along its length, revealed no damage to the insulating rubber but the very thin insulation of the three strands was completely destroyed. This result was considered, perhaps slightly optimistically, as an indication that under normal circumstances the degradation of the cable, when mounted inside the $H V T$, will be a long and slow process. 


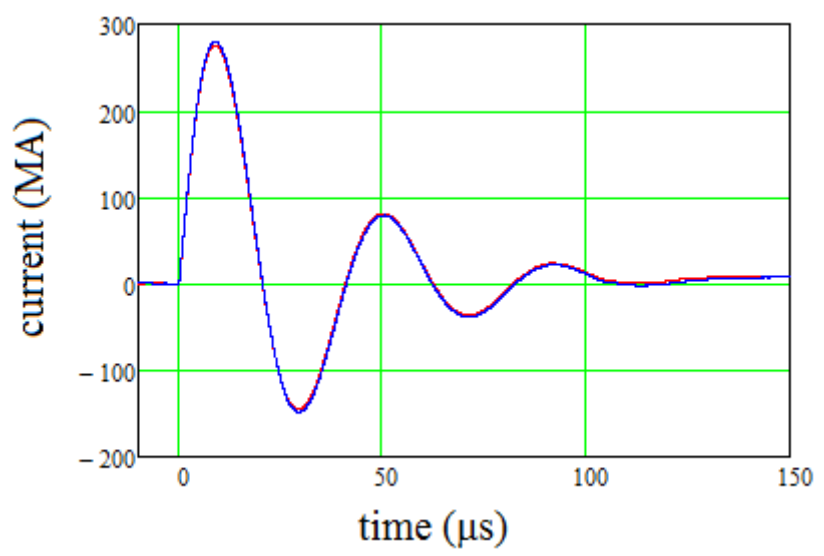

Fig. 7. Quattro bank currents during the two tests of the high-voltage cable; the two traces are practically indiscernible.

\section{8) Manufacture and mounting of the coaxial HVT}

Both the manufacture of the coaxial HVT and its mounting inside the $20 \mathrm{ft}$ container were challenging and Figs 8-11 show various stages of this process. Following this, an intensive test program was performed without raising any issues.

\section{B. Development of the high-voltage diode}

\section{1) The role of the $H V$ diode}

With no switch in the secondary winding circuit (i.e., $S_{2}$ closed from the beginning of the bank discharge) an emf $=-M_{P S} d I_{P} / d t$ is generated (where $d I_{P} / d t>0$ represents the time rate-of-change of the primary winding circuit current), driving the load system with a negative voltage. When the $E W A$ opens, the current falls rapidly (i.e., $\left.d I_{P} / d t<<0\right)$ generating a corresponding emf $>0$ and the system load voltage eventually becomes positive resulting in a bi-polar output. If however a closing switch is used as a HV diode, it must firstly withstand the negative voltage impulse and close at a relatively low positive voltage to optimize the rise time of the load system current after $E W A$ opens.

It is interesting to note that, if $S_{2}$ does not close during a shot, the open circuit emf may attain values well in excess of $1 \mathrm{MV}$, and the $H V T$ would almost certainly suffer an internal electrical breakdown!

With the helical HVT based generator, an existing HV closing switch [5] was firstly used as a diode, but this was later abandoned because it requires pressurized $S F_{6}$ and operation under oil. Once the use of oil was abandoned, a novel HV diode capable of operating in ambient air was required, with the principal aim during its design and preliminary testing being to ensure that it could withstand a high negative voltage of up to $-300 \mathrm{kV}$ and at the same time close easily at about $+140 \mathrm{kV}$. Preliminary tests were undertaken at Pau University (France) to determine the optimum geometrical configuration of the novel HV diode, using similar temporal characteristics of the loading voltage that were similar to those generated when the unit forms part of the high-energy high-power generator.

2) Preliminary test arrangement

The HV diode of Fig. 12(a) is essentially a rod/plate configuration, operated in ambient air with the metallic plate

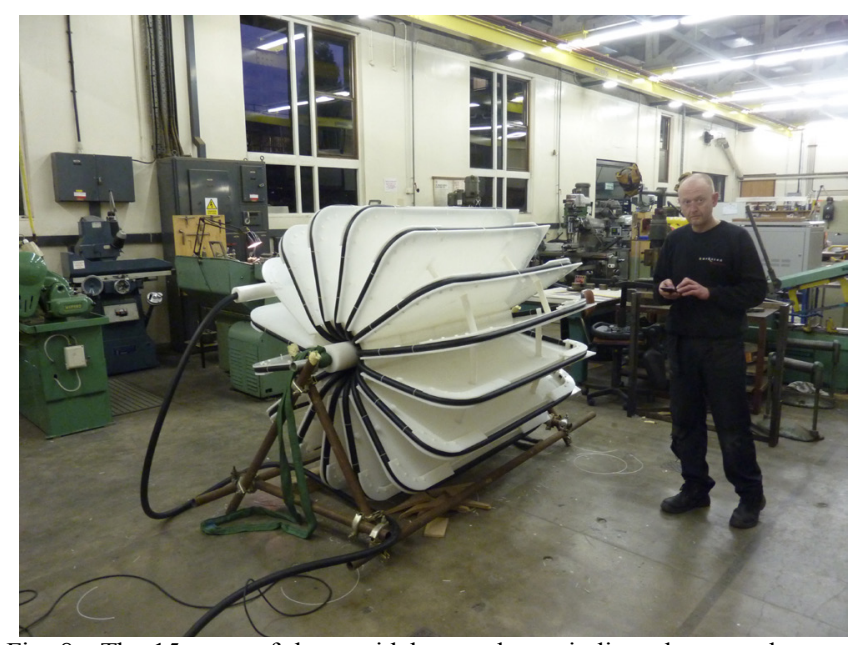

Fig. 8. The 15 turns of the toroidal secondary winding; the central part of the coaxial primary winding, already installed, can also be seen.

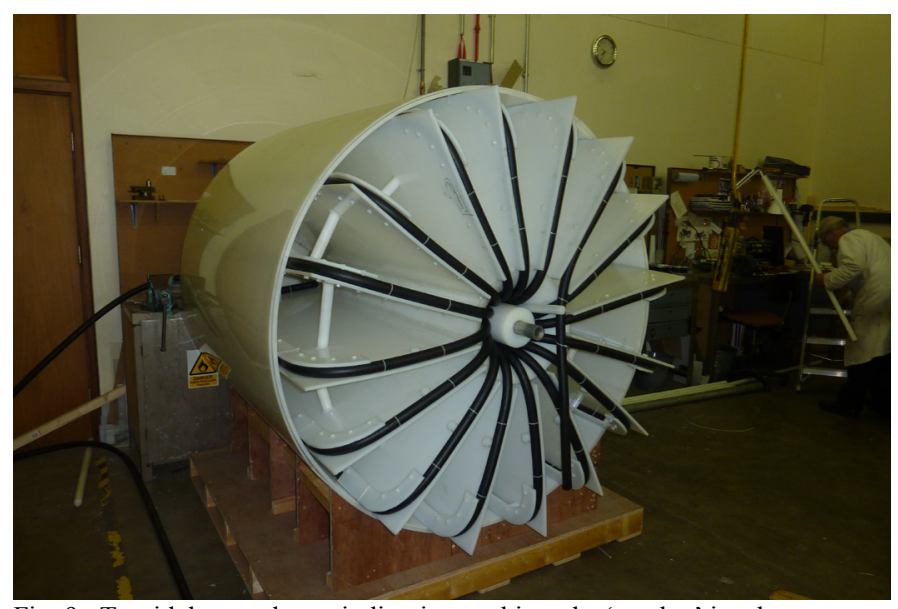

Fig. 9. Toroidal secondary winding inserted into the 'top-hat' insulator.

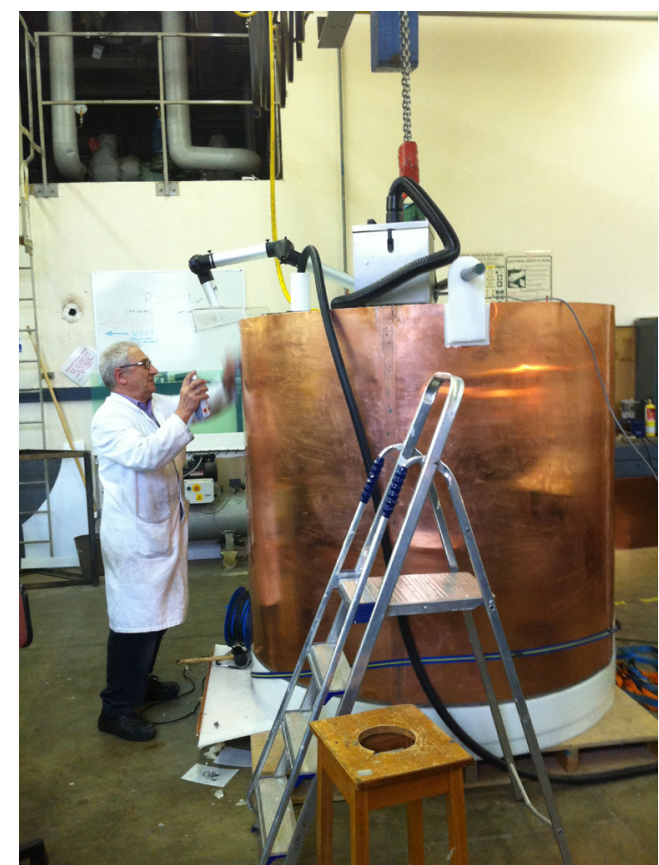

Fig. 10. Last touches on the outer part of the coaxial primary winding, after being mounted onto the 'top-hat' insulator of Fig. 9. 


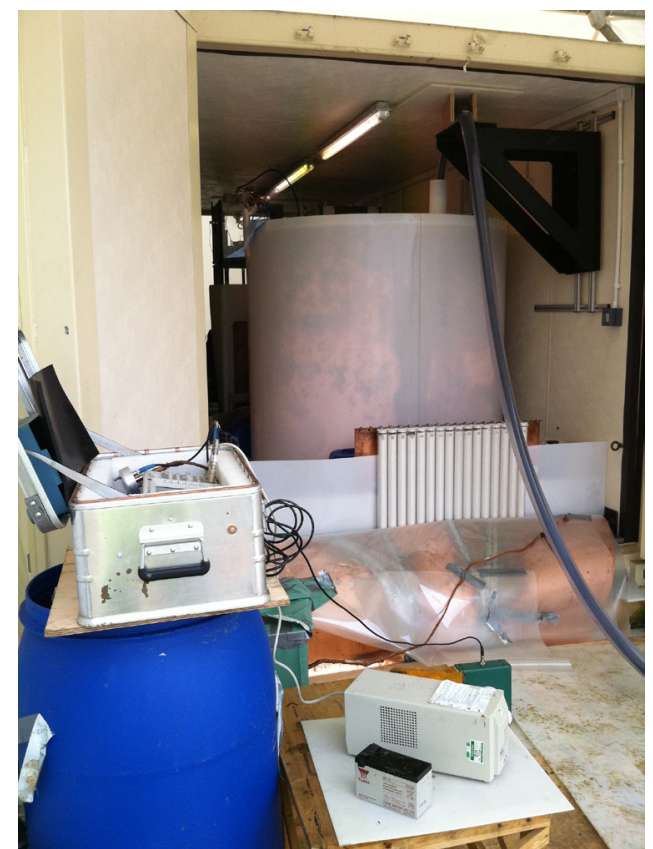

Fig. 11. Coaxial HVT mounted inside the $20 \mathrm{ft}$ container; both the EWA and the $H V T$ output cable are clearly seen.

positioned above the rod and held in position by a stack of disc isolators suspended from a gantry. The plate/rod separation distance $\mathrm{d}$ could be adjusted between $100 \mathrm{~mm}$ and $400 \mathrm{~mm}$ and the rod was mounted on a table and connected to a Marx generator via a long thick copper sheet (see Fig. 12(b)), via a low-inductance transmission line (four parallel-connected $\mathrm{HV}$ cables) coupled to the laboratory ground.

3) Test Marx generators and HV diagnostics

Various high-voltage waveforms were applied from two Marx generators. The first unit (termed $M l$ ) is a $1 \mathrm{MV}, 17 \mathrm{~kJ}$, ten stage generator producing $3 \mu$ s rise time impulses with a characteristic time decay of 3,500 $\mu \mathrm{s}$. The second $400 \mathrm{kV}, 16 \mathrm{~J}$ generator (termed $M 2$ ) produces $1.2 \mu$ s rise time impulses with a characteristic time decay of $80 \mu \mathrm{s}$.

The following voltage sensors were used during the HV diode studies:

- a North Star high-voltage probe type $V D-300$ [12];

- a unit comprising of a North Star high-voltage probe type $P V M-3$ [12] connected at the output of a homemade capacitive divider (10 MHz, $40 \mathrm{pF}, 1 \mathrm{MV})$, with an overall attenuation ratio of $1 / 24,500$.

The two voltage probes were connected to a $1 \mathrm{GHz}$ Tektronix [13] oscilloscope, operated inside a Faraday cage and powered by an UPS unit.

\section{4) Experimental results during preliminary testing the $\mathrm{HV}$} diode

To aid the design of the HV diode, various experimental tests were performed with the aim of determining the gap distance $d$ that allows the switch to withstand $-300 \mathrm{kV}$ and to close at $+140 \mathrm{kV}$. Only the essential results are presented below.

Fig. 13(a) shows that when a negative voltage pulse is applied by $M 1$, breakdown occurs at a voltage $-310 \mathrm{kV}$ for a gap distance of $d_{n}=200 \mathrm{~mm}$. Fig. 13(b) demonstrates that using M2, and for $d_{p}=130 \mathrm{~mm}$, the breakdown is recorded at
$+140 \mathrm{kV}$. During the high-energy generator tests described later, the gap was fixed at between $180 \mathrm{~mm}$ and $200 \mathrm{~mm}$.

5) 3-D electrostatic simulations

The CST EM Studio 3-D electrostatic solver [14] includes solver modules ideally suited to the analysis of static and low frequency devices and was therefore used to gain an improved understanding of the functioning of the HV diode. Both experimental conditions outlined above were simulated, with Fig. 14 presenting 2-D and 3-D views of the electric field distribution for negative polarity. Figs. 15 and 16 show the voltage evolution and the electric field distribution along the vertical central axis of the arrangement. The tip of the rod corresponds to the origin $z=0 \mathrm{~mm}$ with the plate situated at $z$ $=d_{n}=200 \mathrm{~mm}$ for the negative polarity test and $z=d_{p}=$ $130 \mathrm{~mm}$ for the positive polarity test. The results show that the electric field generated in the immediate vicinity of the rod is very strong i.e., $280 \mathrm{kV} / \mathrm{cm}$ for the negative polarity and $80 \mathrm{kV} / \mathrm{cm}$ for positive polarity. Thereafter it decreases exponentially towards the metal plate, where it becomes only $9 \mathrm{kV} / \mathrm{cm}$ for the negative polarity and $5.7 \mathrm{kV} / \mathrm{cm}$ for the positive polarity. It is important to note that the static electric field magnitude, as considered by the software, is not polarity dependent and but only changes due to the geometry of the two electrodes.

6) Analysis

To initiate the electrical discharge, the first condition is related to the electrical field intensity in the immediate vicinity of the rod. In air, the homogeneous DC breakdown field is estimated at $30 \mathrm{kV} / \mathrm{cm} / \mathrm{bar}[15,16]$ although it is much greater under pulsed conditions when a spark-gap can withstand 2-3 times the voltage under DC conditions [17]. The value of the overvoltage is a function of the gas composition, the gap spacing, the polarity and rise-time of the voltage impulse and is attributed to the delay introduced (i.e., statistical time-lag) while waiting for a seed electron to appear $[18,19]$. In the present test conditions, the breakdown is required during the positive rise of the transformer voltage, when the time allowed for the seed electrons to appear is short (a few $\mu \mathrm{s}$ ) and therefore the stability and the reproducibility of the load output pulse is very much improved. Since the level of the overvoltage will increase as the pulse rise-time reduces [18] it should be possible, by applying a fast pulse, to achieve significant overvoltage and subsequent ionisation of a sparkgap, leading to the rapid collapse of the channel.

Additionally, in air, propagation of a breakdown is attributed to the discharge propagation with the positive streamers described by a model that considers the head of the streamer as a sphere with a concentrated positive charge [20, 21]. The energy balance at the head determines the propagation of the streamer, and there is a propagated electric field in which the streamer can continue to grow without losing or gaining charges. The values of this field are $5 \mathrm{kV} / \mathrm{cm} / \mathrm{bar}$ for positive polarity and $18 \mathrm{kV} / \mathrm{cm} / \mathrm{bar}$ for negative polarity, which explains the polarity dependence of the breakdown of the present HV diode. The molecular binding forces in air are sufficiently low for the negative space charge behind the streamer to be sufficiently far away for the assumption of a unipolar space charge to be justified and the contribution of the space charge to be decisive. The space charge field could be taken into account by a microscopic 


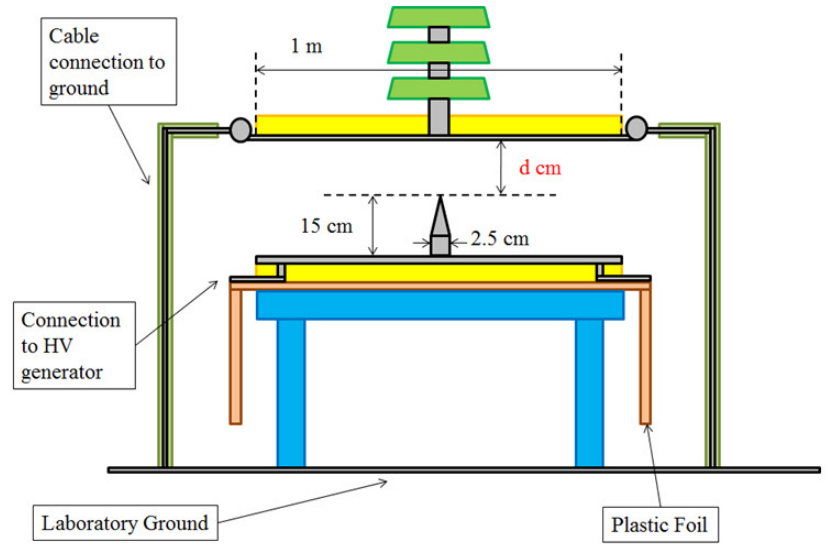

a)

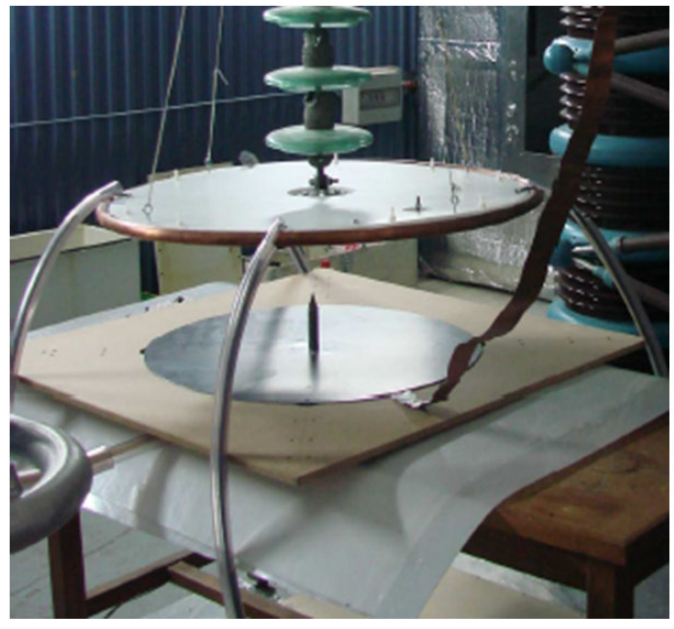

b)

Fig. 12. a) Arrangement for testing the HV diode (a) schematic (b) during testing.

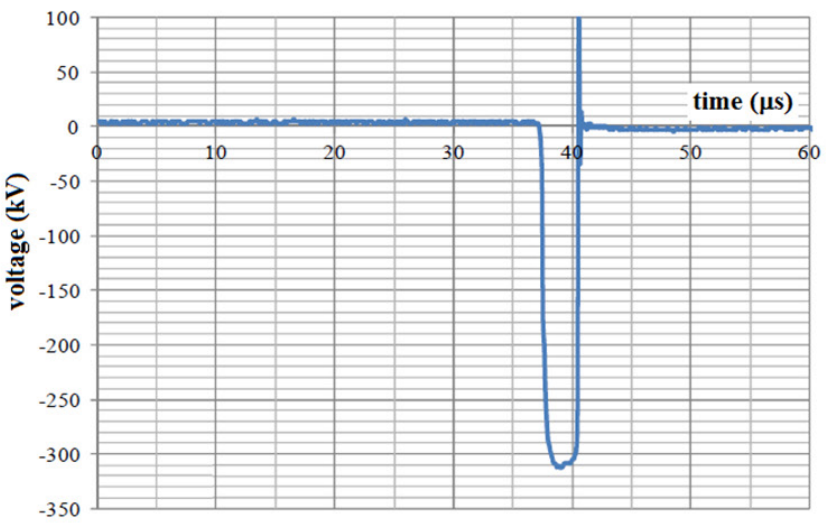

a)

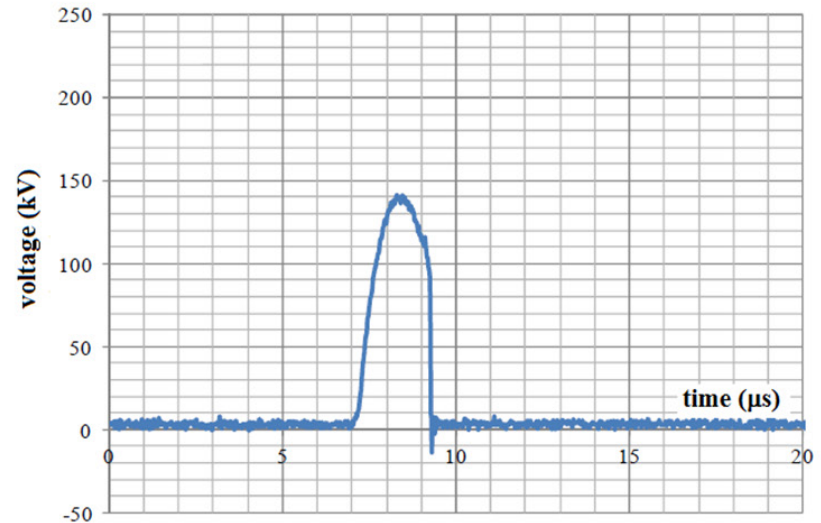

b)

Fig. 13. Results from testing the HV diode (a) closure at $-310 \mathrm{kV}$ (b) closure at $+140 \mathrm{kV}$

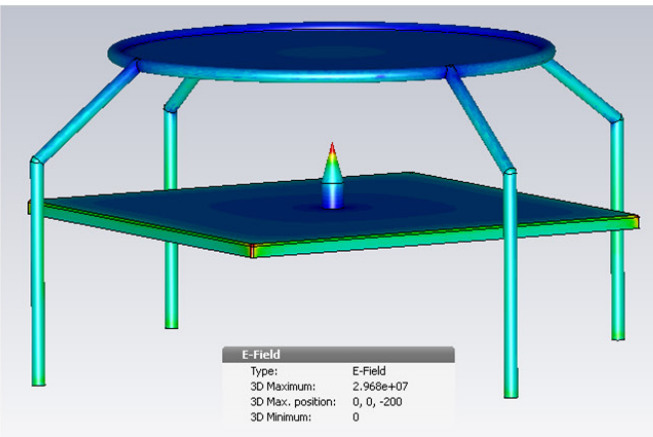

a)
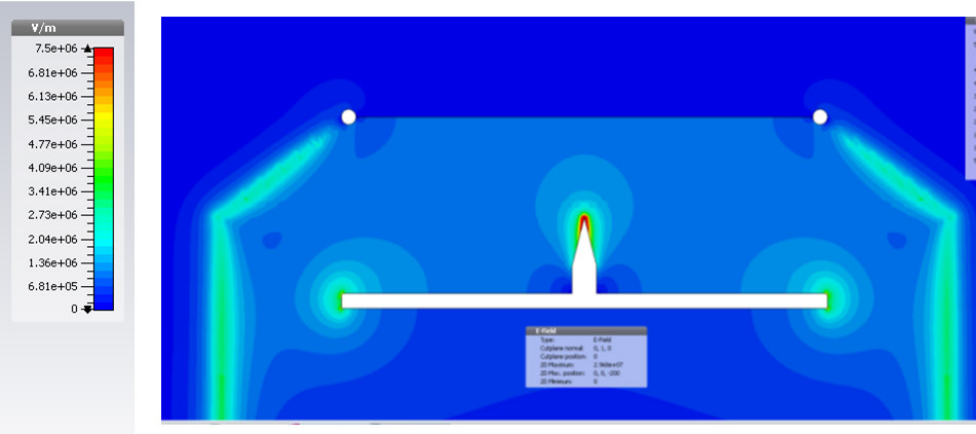

b)

Fig. 14. Electric field distribution in negative polarity obtained with CST software a) 3-D view for an applied voltage of $-310 \mathrm{kV}$ and $\mathrm{b}$ ) 2-D representation. 


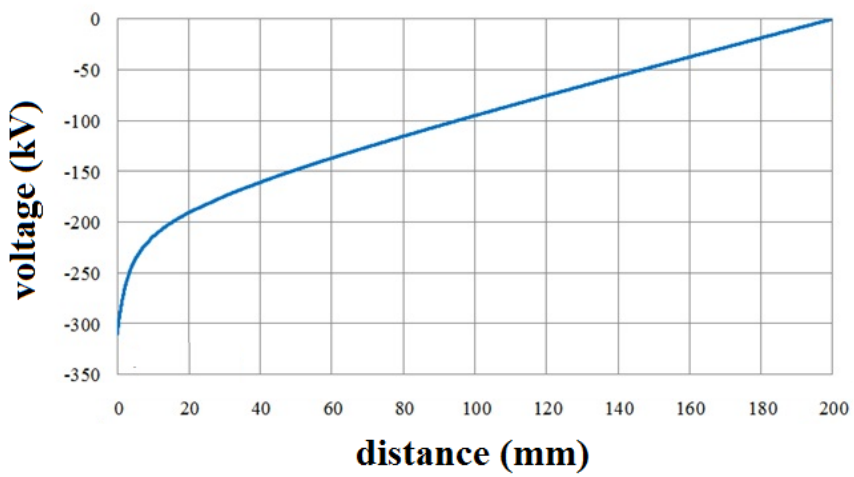

a)

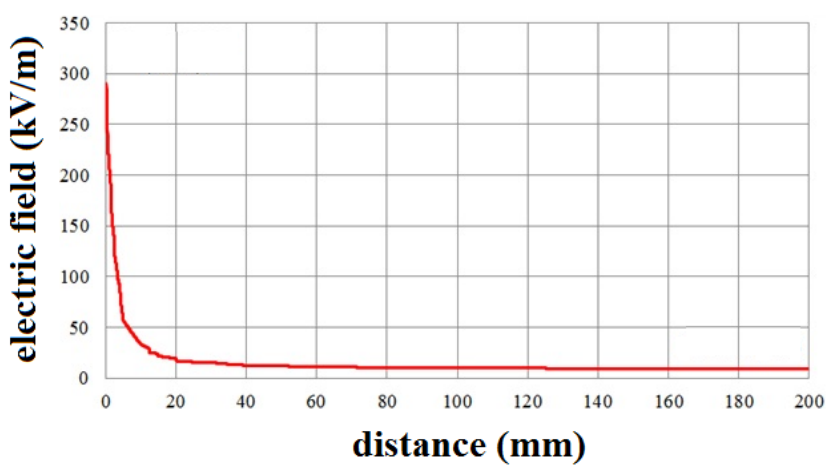

b)

Fig. 15. Results from 3-D electrostatic simulations for negative polarity $\left(d_{n}=200 \mathrm{~mm}\right)$ a) voltage and b) electric field distribution along the axis.

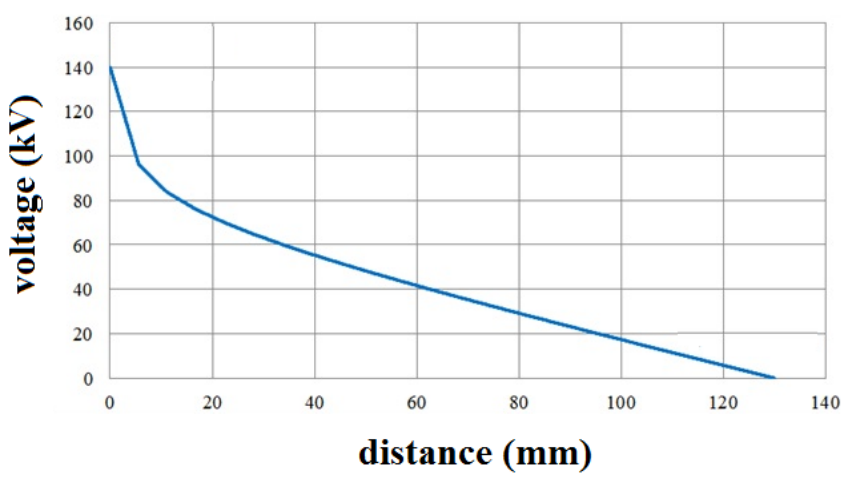

a)

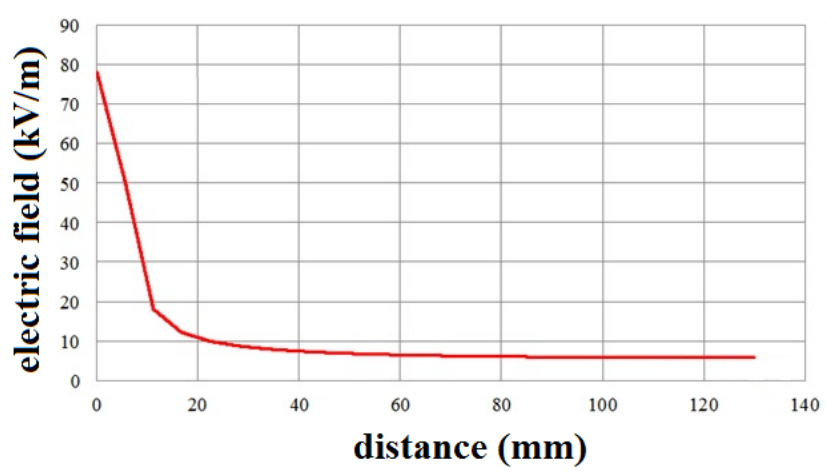

b)

Fig. 16. Results from 3-D electrostatic simulations for positive polarity $\left(d_{p}=130 \mathrm{~mm}\right)$ a) voltage and $\left.\mathrm{b}\right)$ electric field distribution along the axis.

model, but this is beyond the scope of the present study. The spatial distributions of the electric field in Figs. 15(b) and 16(b) confirm the validity of the above argument. For positive polarity, the electric field in the immediate vicinity of the rod reaches $80 \mathrm{kV} / \mathrm{cm}$, greater than the critical field in air of $30 \mathrm{kV} / \mathrm{cm}$ because of the pulse conditions, and the discharge can be initiated. After this, the electric field remains above the propagation field of the streamers in air of about $5 \mathrm{kV} / \mathrm{cm}$ for this polarity, and a breakdown can occur. For negative polarity at $-310 \mathrm{kV}$, the electric field in the vicinity of the rod is sufficiently strong and allows the electric field along the axis to be maintained sufficiently high to initiate a breakdown.

\section{TESTING THE HIGH-ENERGY HIGH-CURRENT GW GENERATOR}

The diagnostic equipment used in testing included:

- a magnetic pick-up probe mounted in a transmission line tunnel, calibrated in situ and used to measure $d I_{P} / d t$. Following a test, the current waveform $I_{P}(t)$ is obtained by numerical integration;

- a Pearson current monitor [22] model 3025 for the direct measurement of the load current;
- three North-Star high-voltage probes [12]: type $P V M-6$ for the EWA, type $V D-300$ for the load and type MEGA-1.2 for the HVT output

The sensors were attached to $300 \mathrm{MHz}$ (or $500 \mathrm{MHz}$ ) Tektronix [13] oscilloscopes, powered either by internal batteries or UPS units.

\section{A. High-power bipolar-mode operation}

In this mode switch $S_{2}$ is closed from the beginning of the capacitor bank discharge i.e., the load system is at all times attached to the generator. In the example considered here both the load self-inductance $L_{L}=25 \mu \mathrm{H}$ and its resistance $R_{L}=$ $36 \Omega$ remain constant during the shot. The load current is shown in Fig. 17 and the energy balance in Fig. 18. The generator provides the system with a peak power close to $3 \mathrm{GW}$, maintains the power in excess of $1 \mathrm{GW}$ for almost $4 \mu \mathrm{s}$ and deposits a load Joule energy in excess of $23 \mathrm{~kJ}$.

\section{B. Detailed analysis of single-mode operation}

In this mode the switch $S_{2}$ acts like a HV diode, attaching the load system only when the voltage in the secondary winding becomes positive. 


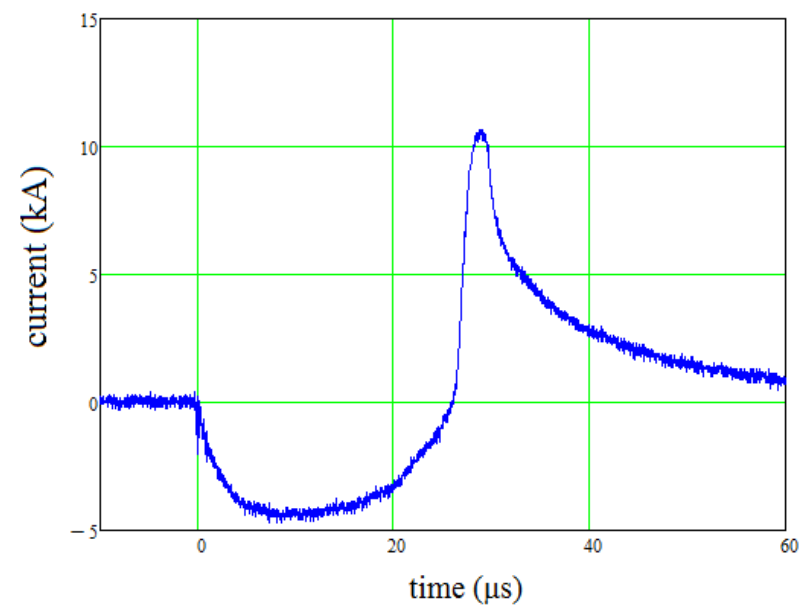

Fig. 17. Current delivered to the load system during bi-polar mode operation; both the load self-inductance $L_{L}=25 \mu \mathrm{H}$ and its resistance. $R_{L}(t)=36 \Omega$ are constant during the shot.

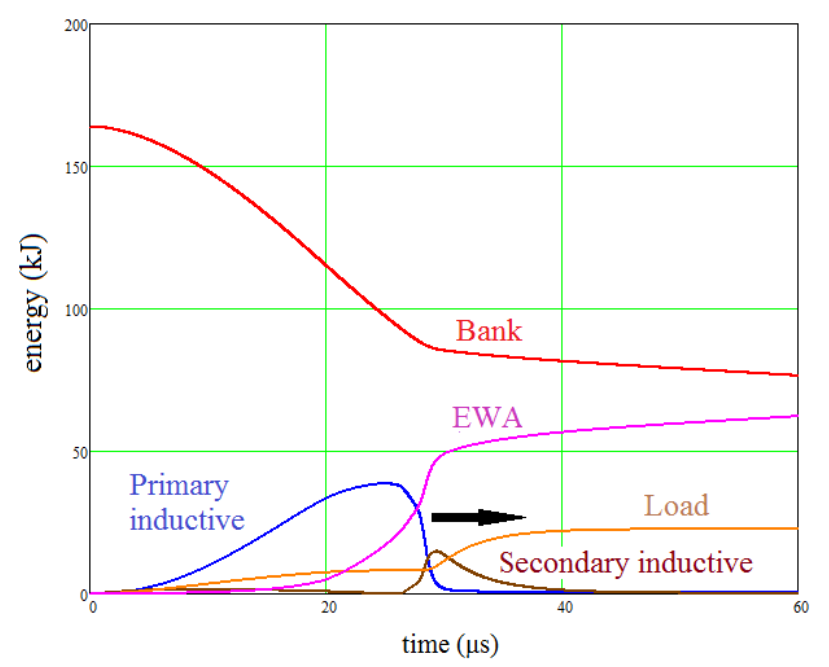

Fig. 18. Energy balance during bi-polar mode operation; the arrow indicates the flow of energy: from the magnetically stored in the primary winding self-inductance to the Joule deposited in the load, hence the term 'inductive storage'.

The first-order differential equations used to simulate the operation of the inductive-storage system of Fig. 1 are:

a) when $S_{1}$ is closed and $S_{2}$ is open, $I_{E W A}=I_{P}$ and $I_{S}=0$ :

$V_{o}-\frac{Q}{C}=\left(L+L_{P}\right) \frac{d I_{P}}{d t}+\left(R+R_{E W A}\right) I_{P}$

$\frac{d Q}{d t}=I_{P}$

$\frac{d W}{d t}=\frac{I_{P}^{2} R_{E W A}}{m_{E W A}}$

When the voltage across the switch $S_{2}$, calculated as $V_{S_{2}}=-M_{P S} \frac{d I_{P}}{d t}+R_{E W A} I_{p}$, reaches a pre-determined positive value the switch closes and the differential equations are changed as presented below. b) when $S_{1}$ is closed and $S_{2}$ is closed; $I_{E W A}=I_{P}-I_{S}$

$$
\begin{aligned}
& V_{o}-\frac{Q}{C}=\left(L+L_{P}\right) \frac{d I_{P}}{d t}+R I_{P}+R_{E W A}\left(I_{P}-I_{S}\right)+M_{P S} \frac{d I_{S}}{d t} \\
& 0=\left(L_{L}+L_{S}\right) \frac{d I_{S}}{d t}+R_{L} I_{S}-R_{E W A}\left(I_{P}-I_{S}\right)+M_{P S} \frac{d I_{P}}{d t} \\
& \frac{d Q}{d t}=I_{P} \\
& \frac{d W}{d t}=\frac{\left(I_{P}-I_{S}\right)^{2} R_{E W A}}{m_{E W A}}
\end{aligned}
$$

In the equations above $Q$ is the charge injected into the circuit by the capacitor bank and $W$ is the specific Joule energy i.e., the energy deposited in the EWA mass $m_{E W A}$. The EWA resistance $R_{E W A}$, which depends only on $W$, is obtained from a phenomenological model for exploding wires similar to that presented in [3]. However, in [3] the wires were relatively thin and operated in air while the present model, presented in Fig. 19, is for thicker exploding wires operated in sand. During computation, a number is obtained for each value of $W$, representing the dynamic resistance i.e., the ratio between the required 'hot' resistance and the initial 'cold' resistance of the wires measured immediately before the shot.

Figs. 20-24 compare detailed experimental data that enables the dynamic characteristics to be obtained for a load system with a constant self-inductance $L_{L}=25 \mu \mathrm{H}$ and a time-varying resistance $R_{L}(t)$ decreasing linearly in $250 \mathrm{~ns}$ from $100 \Omega$ to $20 \Omega$. The rise time of the load current is less than $2 \mu \mathrm{s}$. It is important to note that when the load system is coupled at $V_{S_{2}}=323 \mathrm{kV}$ (see Fig. 23), inductive effects generate in the secondary winding of the $H V T$ a peak voltage reaching $-M_{P S} \frac{d I_{P}}{d t}+L_{S} \frac{d I_{S}}{d t}=553 \mathrm{kV}$. This unwanted phenomenon is the reason why the design of a $H V T$ to produce a peak load voltage in excess of $400 \mathrm{kV}$, must take into account that the peak voltage in the secondary winding exceeds $600 \mathrm{kV}$ !

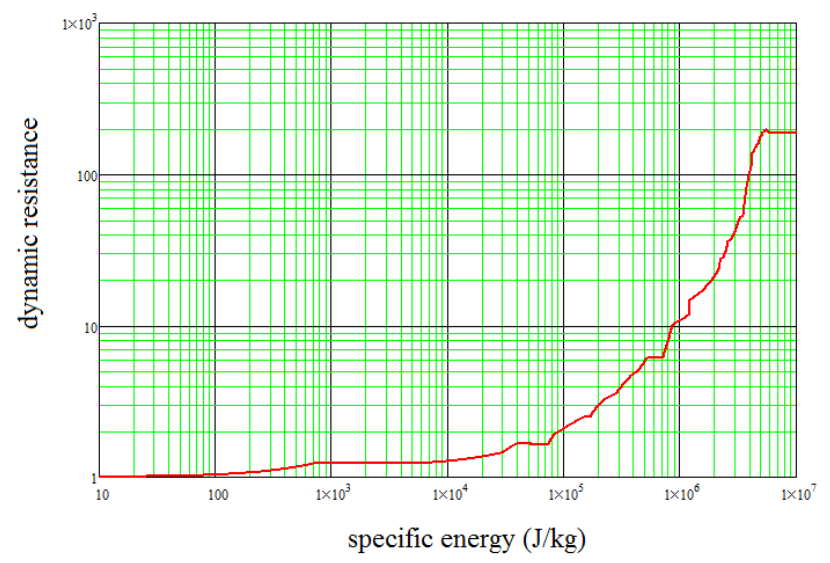

Fig. 19. Phenomenological $E W A$ model for thick wires fired in quartz sand.

\section{Powering extremely large self-inductance systems}

In the final example, similar to that presented above, the load system has an extremely large constant self-inductance $L_{L}$ $=50 \mu \mathrm{H}$ and a dynamic resistance $R_{L}(t)$ falling from $30 \Omega$ to $10 \Omega$ in $4 \mu$ s. The principal results shown in Figs. 25 and 26 confirm that the generator is capable of maintaining an 


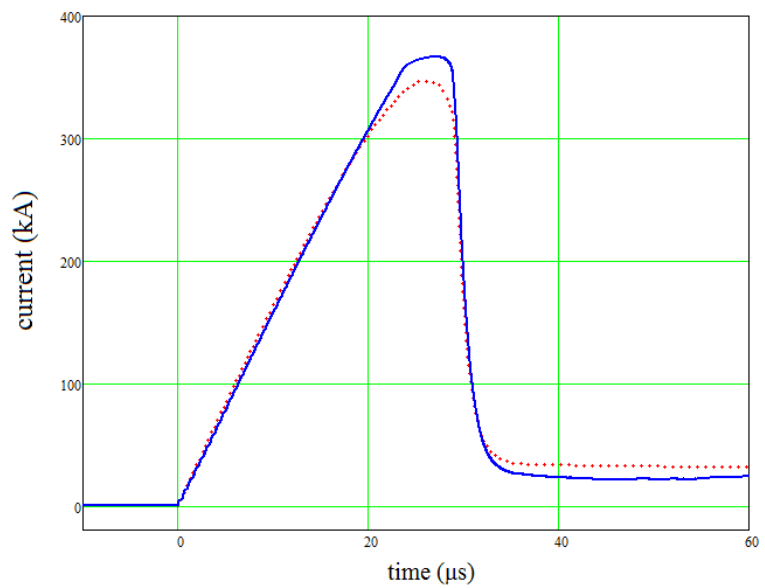

a)

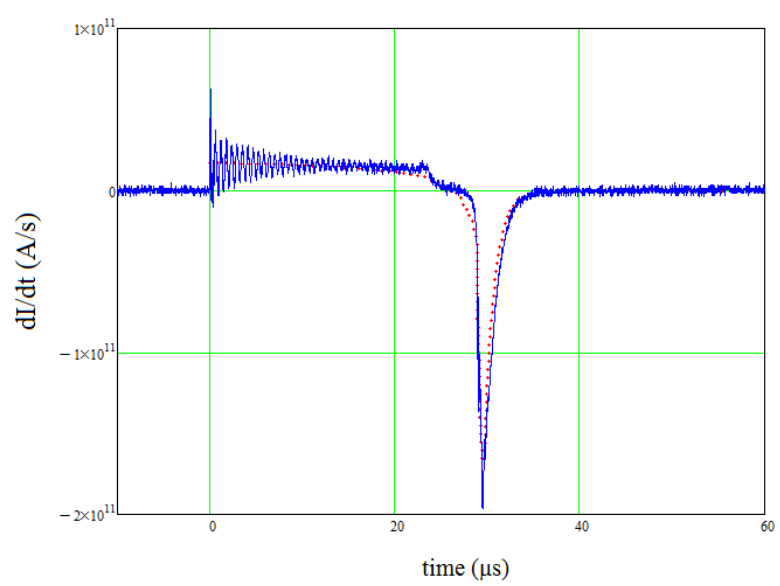

b)

Fig. 20. a) Time dependence of primary winding circuit current and b) its time rate-of-change. Continuous lines: experimental data; dotted lines: theoretical predictions.

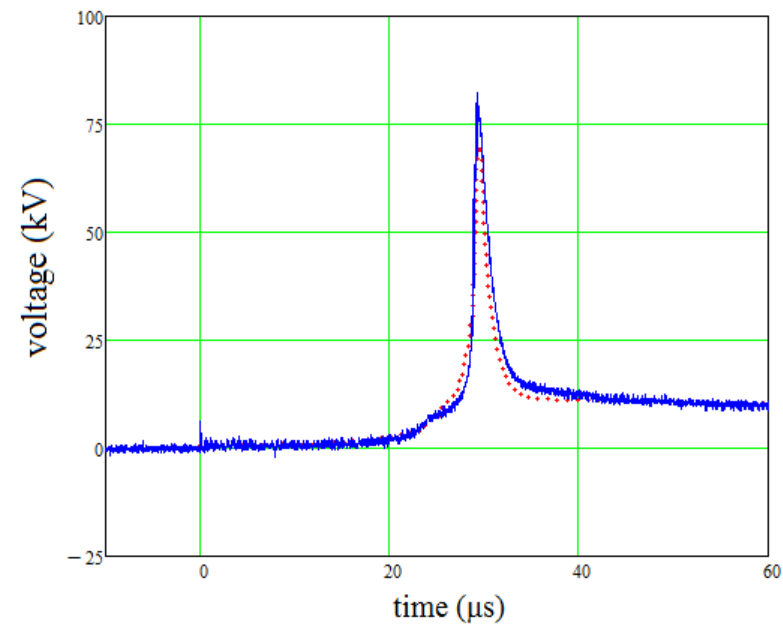

Fig. 21. Voltage across $E W A$ (16 wires mounted in parallel, each $500 \mu \mathrm{m}$ thick and $300 \mathrm{~mm}$ long, fired in quartz sand). Continuous line: experimental data; dotted line: theoretical prediction using the model shown in Fig. 19.

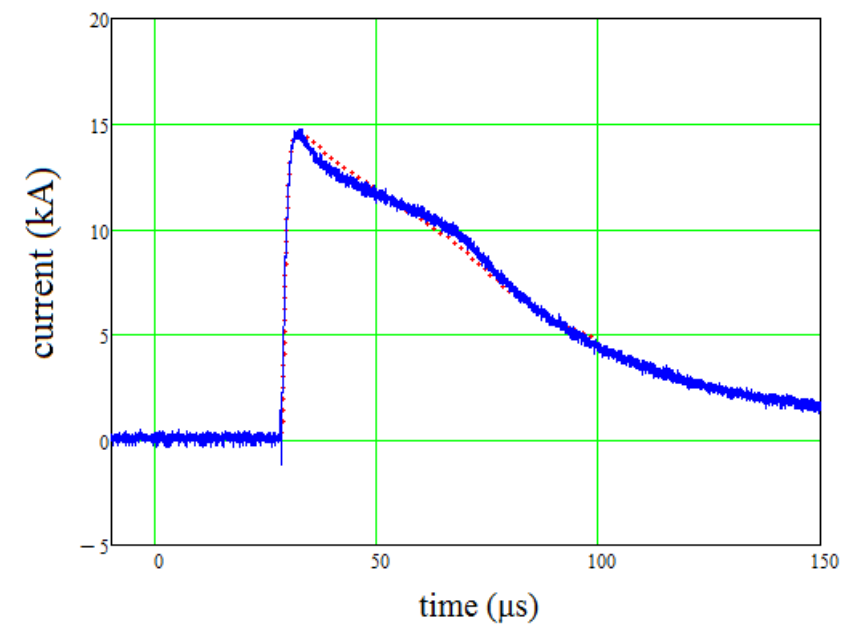

Fig. 22. Current delivered to the load system during single-mode operation; the load has a constant self-inductance $L_{L}=25 \mu \mathrm{H}$ and a time-varying resistance $R_{L}(t)$ decreasing linearly in $250 \mathrm{~ns}$ from $100 \Omega$ to $20 \Omega$.

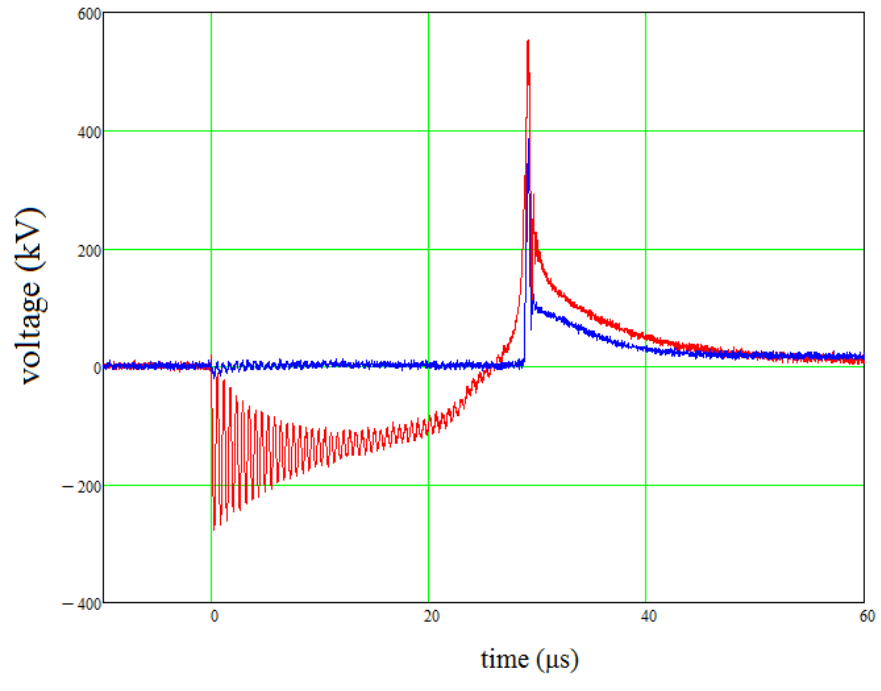

a)

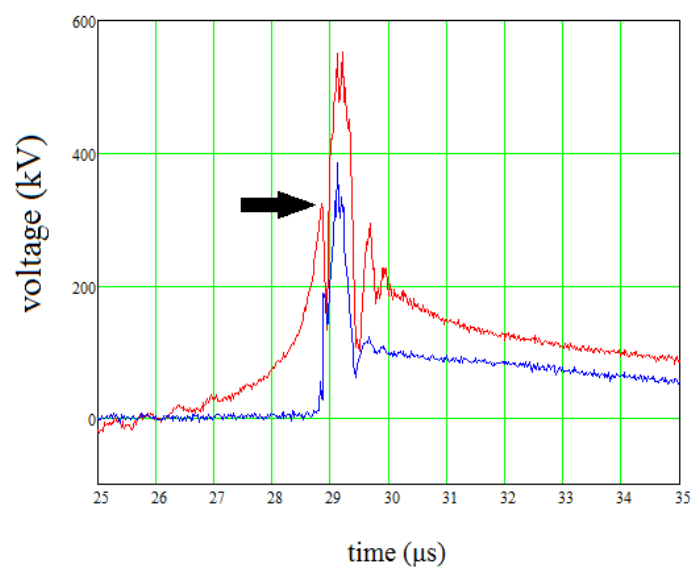

b)

Fig. 23. Voltage across $H V T$ output compared with that across the load for the experiment of Fig. 22. a) complete time history b) zoomed view around the time when the switch $S_{2}$ closes (indicated by an arrow) attaching the load system. The switch removes the long negative precursor seen in a) and at the same time conditions the load current and voltage 


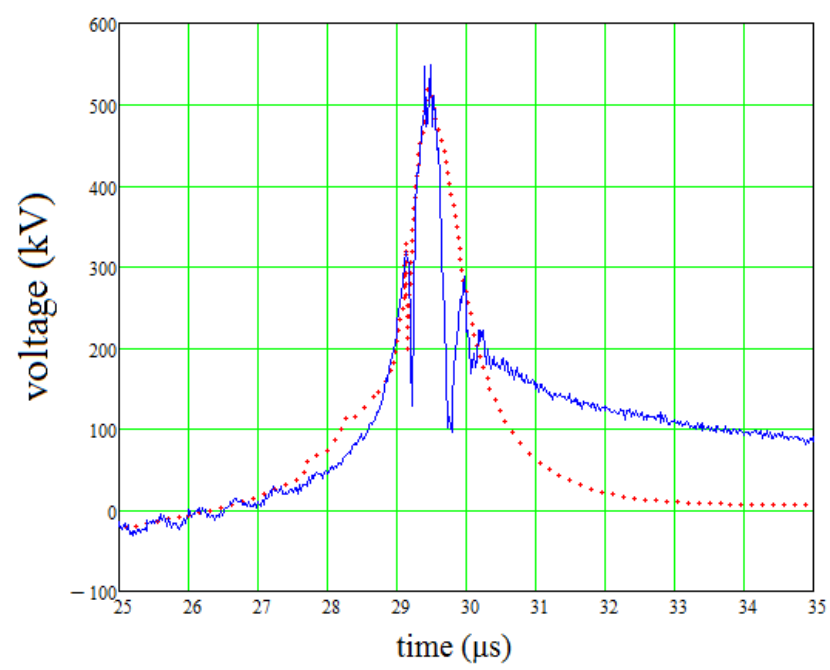

a)

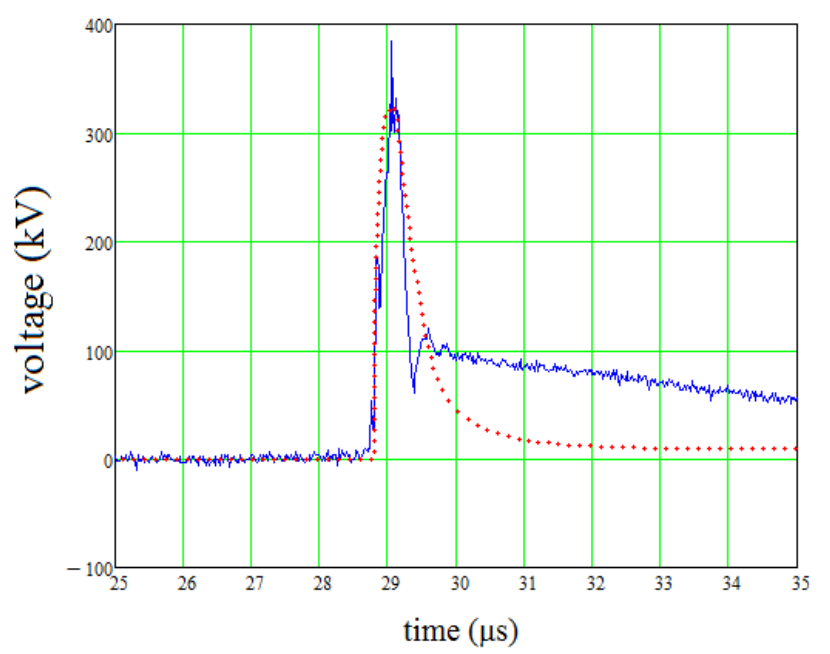

b)

Fig. 24. Comparison between experimental data (continuous lines) for the experiment of Fig. 22 and theoretical predictions (dotted lines) for a) voltage across $H V T$ output b) voltage across the load.

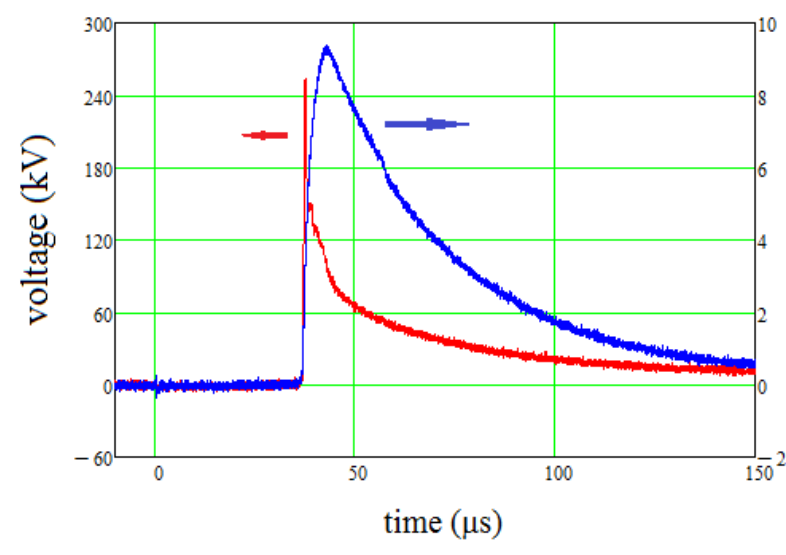

a)

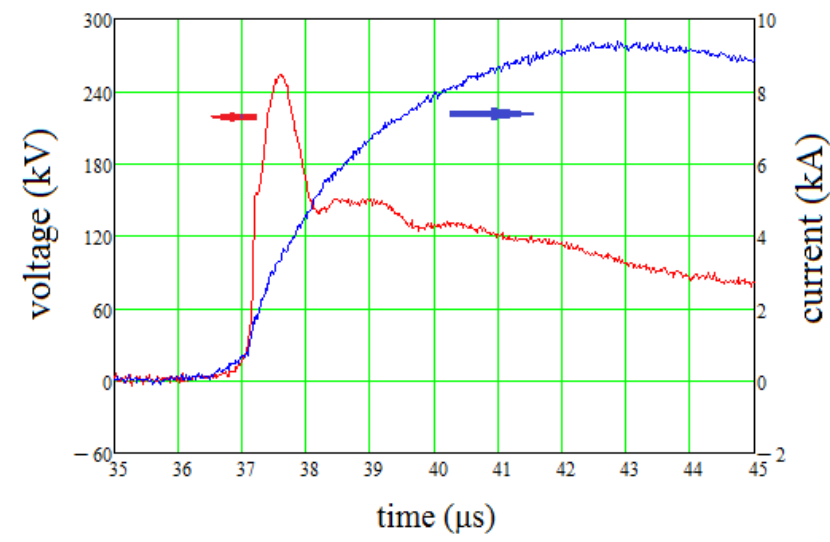

b)

Fig. 25. Current and voltage delivered in single-mode operation to a load system having an extremely large constant self-inductance $L_{L}=50 \mu \mathrm{H}$ and a dynamic resistance $R_{L}(t)$ falling linearly from $30 \Omega$ to $10 \Omega$ in $4 \mu$ s a) complete time history b) zoomed view around the time when the switch $S_{2}$ closes.

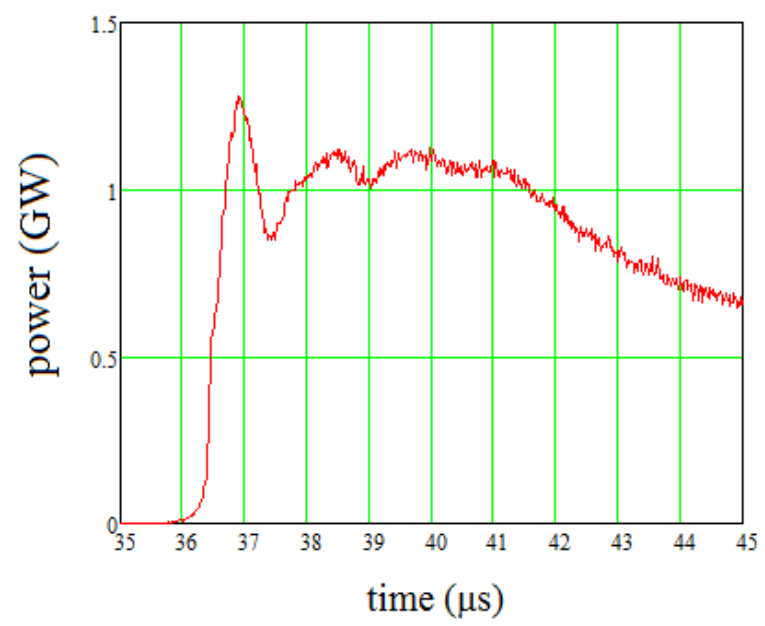

Fig. 26. Electrical power delivered to the load system after the switch $S_{2}$ closes and corresponding to data in Fig. 25. electrical power output in excess of $1 \mathrm{GW}$ for more than $5 \mu \mathrm{s}$, while depositing more than $15 \mathrm{~kJ}$ of Joule energy and Fig. 27 presents stills from a movie with 1000 frames/s, showing the diode plasma dynamics during the shot.

\section{CONCLUSIONS}

A unique generator, capable of driving a system with a selfinductance of many tens of $\mu \mathrm{Hs}$ and a resistance of tens of $\Omega \mathrm{s}$, has been successfully demonstrated at GW power levels. The transportable pulsed power source, mounted in a container, includes a novel design of a coaxial 0.6 MV transformer and a high-power diode, both operating in ambient air. To date the generator has been operated at about $50 \%$ of its maximum initial energy and theoretical predictions, very accurate for the existing data, show that peak powers in excess of $3 \mathrm{GW}$ and Joule energies above $40 \mathrm{~kJ}$ can be produced on highinductance, high-resistive load systems. 


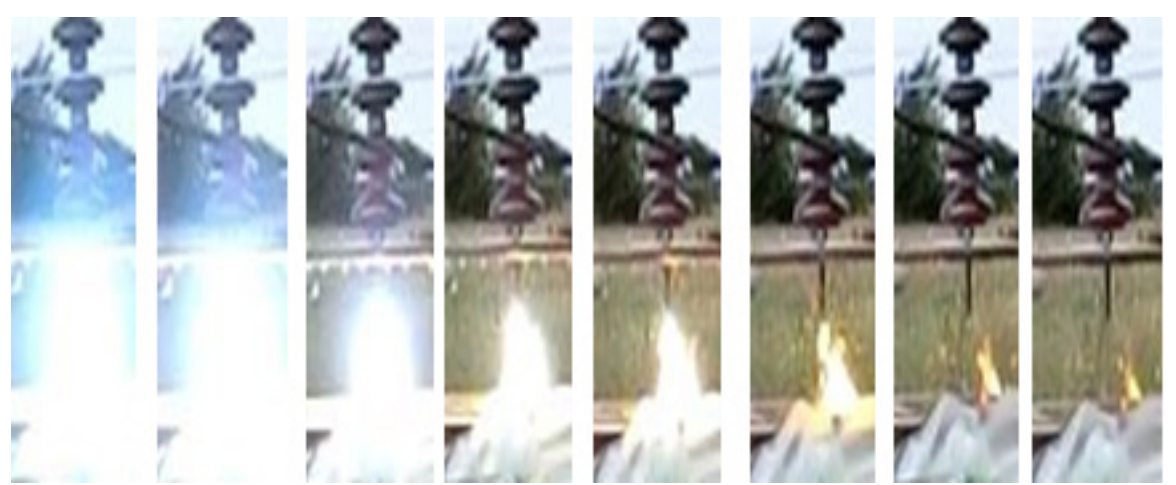

Fig. 27. Dynamics of the HV diode plasma during the shot corresponding to data in Fig. 25 (stills from a 1000 fps movie).

\section{REFERENCES}

[1] B.M. Novac, I.R. Smith, P. Senior, M. Parker, and G. Louverdis 'Transportable High-Energy High-Power Generator', Review of Scientific Instruments, Vol. 81(5), 2010, pp. 1-5

[2] S.A. Nasar and H.H. Woodson, Storage and Transfer of Energy for Pulsed-Power Applications, Proc. Sixth Symposium on Engineering Problems of Fusion Research, San Diego, Ca., November 1975, IEEE Pub. No. 75CH1097-5-NPS, pp. 316-321

[3] R.E. Reinovsky, R.G. Colclaser, J.M. Welby and E.A. Lopez, Energy Storage Transformer Power Conditioning Systems for Megajoule Class Flux Compression Generators, Megagauss Technology and Pulsed Power Applications, Plenum Press, NY and London, 1987, pp. 575-582

[4] M. Giesselmann, J. Zhang, T. Heeren, E. Kristiansen, J. Dickens, D. Castro, D. Garcia and M. Kristiansen, Pulse Power Conditioning with a Transformer for an Inductive Energy Storage System, Proc. $12^{\text {th }}$ IEEE International Pulsed Power Conference, Monterey, Ca, June 1999, pp. 1476-1479

[5] B.M. Novac et al., 'A 10-GW Pulsed Power Supply for HPM Sources', IEEE Trans. Pl. Sci., Vol. 34, 2006, pp. 1814-1821

[6] General Atomics Energy Products (GAEP), http://www.ga.com/energyproducts, last time accessed in November 2013

[7] J. Zhang et al. 'The design of a compact pulse transformer' 12th IEEE Int. Pulsed Power Conf. 1999 Monterey, CA, USA, Ed. Stalling C and Kirbie H, pp. 704-707

[8] C. Fortgang et al., 'A High-Voltage Transformer for Explosive PulsedPower Devices', Proc. Int Conf. Megagauss VIII, Tallahasee, Florida, USA, 1998, Ed. Schneider-Muntau H J, World Scientific, 1998, pp. 648652

[9] J. Luo, J., B.M. Novac, I.R. Smith, and J. Brown, 'Fast and Accurate Two-Dimensional Modelling of High-Current, High-Voltage Air-Cored Transformers", J Phys D: Appl Phys, 38(6), 2005, pp. 955-963

[10] S.M. Wentworth, Fundamentals of Electromagnetics with Engineering Applications, John Wiley \& Sons, Inc, 2005

[11] Essex X-ray, http://www.essex-x-ray.com/hvt cables.html, last time accessed in November 2013

[12] North Star High Voltage, http://www.highvoltageprobes.com/highvoltage-probes, last time accessed in November 2013

[13] Tektronix, http://www.tek.com/, last time accessed in November 2013

[14] Computer Simulation Technology (CST), https://www.cst.com/, last time accessed in November 2013

[15] L. Pecastaing, T. Reess, P. Espel, J. Paillol, A. Gibert, P. Domens, 'Investigation of breakdown characteristics of $\mathrm{N}_{2}, \mathrm{SF}_{6}$ and $\mathrm{N}_{2}-\mathrm{SF}_{6}$ mixtures under pressure', Proc. $11^{\text {th }}$ International Symposium on High Voltage Engineering (ISH) , Vol 3, , London, 1999, pp 224-227

[16] L. Pecastaing, T. Reess, J. Paillol, A. Gibert, P. Domens, "Electrical breakdown studies of pressurised $\mathrm{N}_{2}$ in non uniform fields", European Journal of Physics, Vol 16, 2001, pp 59-69

[17] L. Pecastaing, J. Paillol, T. Reess, A. Gibert, P. Domens, "Design and performance of high voltage pulse generators for ultra-wideband applications", Measurement Science and Technology, vol. 12, 2001, pp 1718-1725

[18] A. Gibert, J. Dupuy, P. Domens, G. Riquel, B. Hutzler., "Dielectric behaviour of $\mathrm{SF}_{6}$ in non-uniform fields", J. Phys. D; Appl. Phys. 26, 1993, p 773-781
[19] L. Pecastaing, A. Gibert, P. Bayle, "Time lag of neutral depopulation of various gases in a point-plane discharge", Proc. 12 ${ }^{\text {th }}$ International Symposium on High Voltage Engineering (ISH), Volume 1, $\mathrm{n}^{\circ} 4-2$, Bangalore (Inde), 2001

[20] I. Gallimberti, “A computer model for streamer propagation”, J. Phys D: Applied Physics, Volume 5, 1972, pp. 2179-2189

[21] I. Gallimberti, N. Wiegart, "Streamer and leader formation in $\mathrm{SF}_{6}$ and $\mathrm{SF}_{6}$ mixtures under impulse conditions, J. Phys D: Applied Physics, Volume 12, 1986, pp. 2351-2379

[22] Pearson Electronics, http://www.pearsonelectronics.com/, last time accessed in November 2013

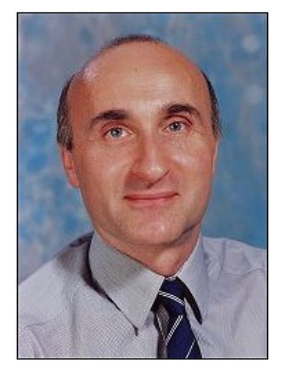

Bucur M. Novac (M'06 - SM'08) received the M.Sc. and Ph.D. degrees in 1977 and 1989, respectively. $\mathrm{He}$ joined the Loughborough University, UK in 1998 and is currently Professor of Pulsed Power. His research interests include compact and repetitive high-power systems, explosively and electromagnetically driven magnetic flux compression generators and their applications, electromagnetic launchers, ultrafast magneto and electro-optic sensors and 2-D modeling of pulsed-power systems.

Prof. Novac is a voting member on the Pulsed Power Science \& Technology Committee in the IEEE Nuclear and Plasma Science Society. He is also a member of the International Steering Committees for both the MEGAGAUSS Conferences and for the Euro-Asian Pulsed Power Conferences. He is also member of the organizing committee for the IEEE International Power Modulator and High Voltage Conference and co-chairman of the UK Pulsed Power Symposium.

Prof. Novac is a Chartered Engineer and a Fellow of The Institution of Engineering and Technology (IET), UK.

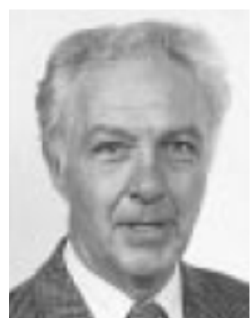

Ivor R. Smith (M'05-SM'11) received both B.Sc. and Ph.D. degrees from the University or Bristol, UK after completing an indentured student apprenticeship at the Witton Works of the General Electric company. $\mathrm{He}$ then became a Lecturer at the University of Birmingham, UK, subsequently being promoted to Senior Lecturer and Reader and being awarded the degree of D.Sc. by the University of Bristol for his continued research contribution. He then moved to Loughborough University, UK to become Professor of Electrical Power Engineering, and served as Head of Department, Dean of Engineering and Pro-Vice Chancellor. For more than 25 years he has been active in research in many aspects of the production, conditioning and utilization of large pulses of electrical energy and his work has brought in very substantial funding from a variety of sources.

Professor Smith is a Chartered Engineer and a Fellow of both the Institution of Engineering and Technology and the Royal Academy of Engineering. 


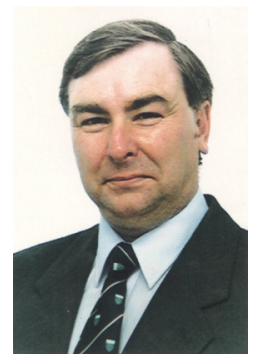

Peter Senior received an Honours Degree in Physics with Electronics from Leicester University. He is a member of the Institute of Physics and a Chartered Physicist. He began his career in the Electronic and Electrical Engineering Department at Loughborough University researching Ultrasonic Nondestructive Evaluation, extending into Nonlinear (Finite Amplitude) Acoustics. He was one of the founder members of the Pulsed Power Research Group. He has worked on Propellant and Explosive Pulsed MHD Generators, and also produced systems to support a Flux Compressor Programme. Other work has included High Efficiency Launchers and the Electromagnetic Protection of Armoured Vehicles. He has produced a number of Transportable High Energy, High Power Systems, varying in size between fitting into a van, and up to two ISO Containers, supplied by diesel generators. This has required expertise in the Health and Safety Aspects of integrating Pulsed Power systems with the equipment of sponsoring and collaborating bodies.

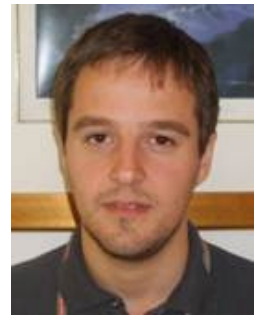

Mike Parker is a pulsed power engineer currently working for the BAE Systems Advanced Technology Centre UK. He studied at Loughborough University UK from 2003 to 2012, completing an undergraduate degree in electronic and electrical engineering and following this with a $\mathrm{PhD}$ in pulsed power. Mike is interested in all manner of energy and power technologies, and has previously worked for the Centre for Renewable Energy Systems Technology, and the Energy Technologies Institute, both based in Loughborough. He is interested in the physics and applications of pulsed power technology, is the author of several papers and a thesis on this fascinating subject, and has contributed to the development of a range of pulsed power sources including low-energy repetitive systems, and highenergy high-current systems.

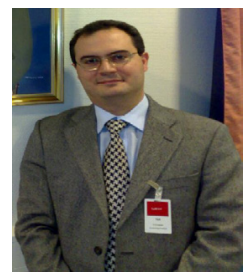

Gerry Louverdis obtained his MSc in Mobile, Personal and Satellite Communications from the University of Westminster, London, UK and his BEng in Electronic Engineering from the Technological University of Crete, Chania, Greece. He is a Chartered Engineer and a Fellow of the Institution of the Engineering and Technology (IET), as well as a registered "European Engineer" within the Federation of National Engineering Associations (FEANI).

$\mathrm{He}$ has wide experience in the engineering and development of both High Power RF \& Telecommunication and Pulsed Power Systems, and involvement in all delivery phases of the engineering life cycle.

Currently he is employed by the UK MOD as technical expert with broad knowledge of the development, integration and successful delivery of state-ofthe-art systems into service in the Defence area of Land, Sea and Air Domains.

He is Principal UK-MOD delegate to various multinational NATO research task groups and currently he is co-chair of the NATO SCI-250 Research Task Group.

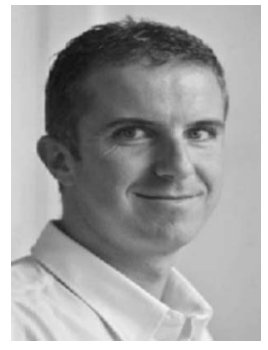

Laurent Pécastaing was born in Bayonne, France, in 1974. He received the Ph.D. degree and the Research Directorship Habilitation in electrical engineering from the Université de Pau et des Pays de l'Adour, Pau, France, in 2001 and 2010, respectively.

$\mathrm{He}$ is currently a Lecturer with the Laboratoire SIAME, Université de Pau et des Pays de l'Adour. His research interests are focused on high-power microwave (HPM) sources, compact pulsed power devices, including pulse-forming lines or Marx generators, and ultrafast transient probes.

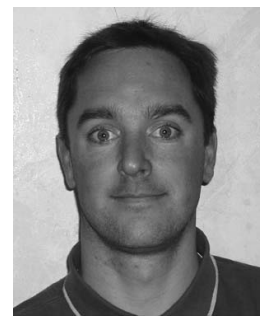

Antoine Silvestre de Ferron was born in Tarbes, France, in 1977. He received the Ph.D. degree in electrical engineering from the Université de Pau et des Pays de l'Adour (UPPA), Pau, France, in 2006. From 2006 to 2008, he was a Researcher with the Atomic Energy Comission (CEA), Le Barp, France - a French-government-funded technological research organization. He is currently an Engineer with the Laboratoire SIAME, UPPA. His research interests include high pulsed power generation for military and civil applications and combined high-voltage transient probes.

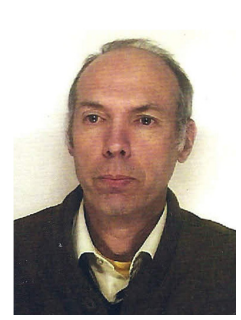

Pascal Pignolet was born in Rennes, France, in 1951. $\mathrm{He}$ received the Ph.D. degree in Gas and Plasma Physics from the University of Orléans, France, in 1980 and the higher Doctorate of Science in 1984 for his work devoted to the spectroscopic study of nonresonant laser-atom interaction. $\mathrm{He}$ is currently a Professor with the University of Pau (France) and with the SIAME laboratory. His main research interest is currently focused on Pulsed Power domain, Materials for the Electrical Engineering and Laser applications.

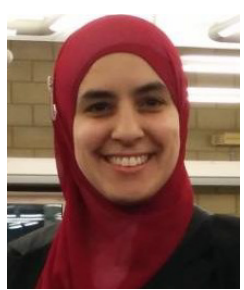

Sonia Souakri received the BS degree in Physics \& Chemistry from Bordeaux University, France, in 2010 and the MS degree in Material Engineering in Chemistry and Physical Chemistry (major Polymer and Colloids) from Pau University, France, in 2012. She is currently pursuing a Ph.D. on electrostatic precipitator and fine particle filtration with the SIAME Laboratory (Department of Electrical Engineering) at Pau University.

She is interested in materials science, high voltage engineering, pulsed power, computer simulation and plasma and gas filtration. 